\title{
Geomorphology and structural geology of Saturnalia Fossae and adjacent structures in the northern hemisphere of Vesta
}

\author{
Jennifer E.C. Scully ${ }^{\mathrm{a}, *}$, A. Yin ${ }^{\mathrm{a}}$, C.T. Russell ${ }^{\mathrm{a}}$, D.L. Buczkowski ${ }^{\mathrm{b}}$, D.A. Williams ${ }^{\mathrm{c}}$, D.T. Blewett ${ }^{\mathrm{b}}$, O. Ruesch ${ }^{\mathrm{d}}$, \\ H. Hiesinger ${ }^{\mathrm{d}}$, L. Le Corre ${ }^{\mathrm{e}}$, C. Mercer ${ }^{\mathrm{c}}$, R.A. Yingst ${ }^{\mathrm{e}}$, W.B. Garry ${ }^{\mathrm{f}}$, R. Jaumann ${ }^{\mathrm{g}}$, T. Roatsch ${ }^{\mathrm{g}}$, F. Preusker ${ }^{\mathrm{g}}$, \\ R.W. Gaskell ${ }^{\mathrm{e}}$, S.E. Schröder ${ }^{g}$, E. Ammannito ${ }^{\text {h }}$, C.M. Pieters ${ }^{\mathrm{i}}$, C.A. Raymond ${ }^{\mathrm{j}}$, the Dawn Science Team \\ a Department of Earth, Planetary, and Space Sciences, University of California, Los Angeles, CA 90095-1567, USA \\ bohns Hopkins University Applied Physics Laboratory, Laurel, MD 20723, USA \\ 'Arizona State University, Tempe, AZ 85004, USA \\ d Institut für Planetologie, Westfälische Wilhelms-Universität, 48149 Münster, Germany \\ e Planetary Science Institute, Tucson, AZ 85719, USA \\ ${ }^{\mathrm{f}}$ NASA Goddard Space Flight Center, Greenbelt, MD 20771, USA \\ ${ }^{\mathrm{g}}$ German Aerospace Center (DLR), 12489 Berlin, Germany \\ ${ }^{\mathrm{h}}$ Istituto di Astrofisica e Planetologia Spaziali, Istituto Nazionale di Astrofisica (INAF/IFSI), 00133 Rome, Italy \\ ${ }^{\mathrm{i}}$ Brown University, Providence, RI 02912, USA \\ jJet Propulsion Laboratory, California Institute of Technology, Pasadena, CA 91109, USA
}

\section{A R T I C L E I N F O}

Article history:

Available online $\mathrm{xxxx}$

\section{Keywords:}

Asteroid Vesta

Asteroids, surfaces

Geological processes

\section{A B S T R A C T}

Vesta is a unique, intermediate class of rocky body in the Solar System, between terrestrial planets and small asteroids, because of its size (average radius of $\sim 263 \mathrm{~km}$ ) and differentiation, with a crust, mantle and core. Vesta's low surface gravity $\left(0.25 \mathrm{~m} / \mathrm{s}^{2}\right)$ has led to the continual absence of a protective atmosphere and consequently impact cratering and impact-related processes are prevalent. Previous work has shown that the formation of the Rheasilvia impact basin induced the equatorial Divalia Fossae, whereas the formation of the Veneneia impact basin induced the northern Saturnalia Fossae. Expanding upon this earlier work, we conducted photogeologic mapping of the Saturnalia Fossae, adjacent structures and geomorphic units in two of Vesta's northern quadrangles: Caparronia and Domitia. Our work indicates that impact processes created and/or modified all mapped structures and geomorphic units. The mapped units, ordered from oldest to youngest age based mainly on cross-cutting relationships, are: (1) Vestalia Terra unit, (2) cratered highlands unit, (3) Saturnalia Fossae trough unit, (4) Saturnalia Fossae cratered unit, (5) undifferentiated ejecta unit, (6) dark lobate unit, (7) dark crater ray unit and (8) lobate crater unit. The Saturnalia Fossae consist of five separate structures: Saturnalia Fossa A is the largest (maximum width of $\sim 43 \mathrm{~km}$ ) and is interpreted as a graben, whereas Saturnalia Fossa B-E are smaller (maximum width of $\sim 15 \mathrm{~km}$ ) and are interpreted as half grabens formed by synthetic faults. Smaller, second-order structures (maximum width of $<1 \mathrm{~km}$ ) are distinguished from the Saturnalia Fossae, a first-order structure, by the use of the general descriptive term 'adjacent structures', which encompasses minor ridges, grooves and crater chains. For classification purposes, the general descriptive term 'minor ridges' characterizes ridges that are not part of the Saturnalia Fossae and are an order of magnitude smaller (maximum width of $<1 \mathrm{~km}$ vs. maximum width of $\sim 43 \mathrm{~km}$ ). Shear deformation resulting from the large-scale (diameter of $<100 \mathrm{~km}$ ) Rheasilvia impact is proposed to form minor ridges ( $\sim 2 \mathrm{~km}$ to $\sim 25 \mathrm{~km}$ in length), which are interpreted as the surface expression of thrust faults, as well as grooves ( $\sim 3 \mathrm{~km}$ to $\sim 25 \mathrm{~km}$ in length) and pit crater chains ( $\sim 1 \mathrm{~km}$ to $\sim 25 \mathrm{~km}$ in length), which are interpreted as the surface expression of extension fractures and/or dilational normal faults. Secondary crater material, ejected from small-scale and medium-scale impacts (diameters of $<100 \mathrm{~km}$ ), are interpreted to form ejecta ray systems of grooves and crater chains by bouncing and scouring across the surface. Furthermore, seismic shaking, also resulting from small-scale and medium-scale impacts, is interpreted to form minor ridges because seismic shaking induces flow of regolith, which subsequently accumulates as minor ridges that are roughly parallel to the regional slope. In this work we expand upon the link between impact processes and structural features on Vesta by presenting findings of a photogeologic, structural mapping study which highlights how impact cratering and impact-related processes are expressed on this unique, intermediate Solar System body.

(c) 2014 Elsevier Inc. All rights reserved.

\footnotetext{
* Corresponding author.

E-mail address: jscully@ucla.edu (J.E.C. Scully).
} 


\section{Introduction}

Vesta is the second most massive asteroid in the Solar System, located in the asteroid belt, with axes measuring $286.3 \pm 0.1 \mathrm{~km}$, $278.6 \pm 0.1 \mathrm{~km}$ and $223.2 \pm 0.1 \mathrm{~km}$ when approximated by an ellipsoid (Russell et al., 2012). Vesta is the only asteroid known to have differentiated to form a core, a mantle and a crust, and is consequently referred to as a protoplanet (e.g. Russell et al., 2012). Vesta is thought to have remained intact since its formation at $\sim 4.56 \mathrm{Ga}$ (McSween et al., 2011), dated by crystallization ages of meteorites interpreted to derive from Vesta: the Howardite, Eucrite and Diogenite (HED) meteorites (McCord et al., 1970).

Vesta has been studied remotely since its discovery by H.M. Wilhelm Olbers in 1807. In 1970, the HED meteorites were proposed to originate from Vesta (McCord et al., 1970). Later, Hubble Space Telescope observations of Vesta identified a large southern impact basin, which could be the source region of the HEDs (Thomas et al., 1997). Further observations showed spectral heterogeneity across the vestan surface (Binzel et al., 1997; Gaffey, 1997; Li et al., 2010). The proposed connection between the HEDs and Vesta was recently confirmed by the observations of the Dawn spacecraft (Russell et al., 2012; De Sanctis et al., 2012; Prettyman et al., 2012; Reddy et al., 2012a). Further introductory information about Vesta is included in the Introductory paper to this Special Issue (Williams et al., this issue).

This paper focuses on the first-order Saturnalia Fossae and second-order adjacent structures, which occur in Vesta's northern hemisphere. Section 2, Background, discusses Vesta's place in structural and geological studies of planetary bodies of different scales. Section 3, Methods, describes the techniques used in this study. Section 4, Results, presents the geological maps produced in this work, along with observations and interpretations of the structural features and geological units identified. Section 5, Discussion, considers interpretations of the main findings in this study, with emphasis on the temporal relationships between the mapped structures and the related impact events. Section 6, Conclusions, summarizes the main findings of this work and their implications for Vesta and broader studies in planetary sciences.

\section{Background}

Vesta's size and surface gravity, $0.25 \mathrm{~m} / \mathrm{s}^{2}$, place it in an intermediate Solar System category between that of the terrestrial planets and small asteroids (e.g. Jaumann et al., 2012). Unlike Earth or Mars, Vesta lacks a protective atmosphere and consequently the dominant geologic process is impact cratering (e.g. Russell et al., 2012; Jaumann et al., 2012; Schenk et al., 2012). On account of this, Vesta's surface is highly cratered (Marchi et al., 2012). The two most prominent impact features are large impact basins near Vesta's southern hemisphere: a younger basin, named Rheasilvia (500 km wide), which partially overlies an older basin, named Veneneia (450 km wide) (Schenk et al., 2012) (Fig. 1).

Previous studies have shown that impact processes not only form numerous craters on Vesta, but also induce the formation of large structural features termed fossae (e.g. Jaumann et al., 2012; Buczkowski et al., 2012; Bowling et al., 2013). These tens of kilometer-scale fossae, which are long, narrow depressions, are observed in the northern hemisphere and in the equatorial regions. Saturnalia Fossa A is dominant in the northern hemisphere group, which are called the Saturnalia Fossae, and Divalia Fossa A is dominant in the equatorial group, which are called the Divalia Fossae (Jaumann et al., 2012) (Fig. 1).

The poles to the planes defined by the Saturnalia Fossae plot in the center of the Veneneia impact basin and the poles to the planes defined by the Divalia Fossae plot in the center of the Rheasilvia impact basin (Buczkowski et al., 2012) (Fig. 2). Therefore, these geometrical relationships imply that the formation of the Veneneia basin likely induced the formation of the Saturnalia Fossae and formation of the Rheasilvia basin likely induced the formation of the Divalia Fossae (Buczkowski et al., 2012).

Numerical modeling of the Rheasilvia-forming impact, into model Vestas with a variety of interior characteristics, finds that there is a concentration of extension at the site of the Divalia Fossae, but that most of the vestan crust experiences complex modes of shear (Bowling et al., 2013). A similar concentration of extension is also found at the site of the Saturnalia Fossae, which arise from the Veneneia impact (Bowling et al., 2013). Thus, it is likely that extension arising from the Veneneia impact formed the Saturnalia Fossae (Buczkowski et al., 2012).

It is proposed that Vesta's differentiation allowed for the formation of the fossae, which are interpreted as graben, because the differentiated interior amplified and reoriented the stresses induced by the impacts (Buczkowski et al., 2012). Such amplification and reorientation does not occur on smaller, undifferentiated asteroids such as Lutetia, Eros and Ida (Buczkowski et al., 2012). Thus, smaller-scale lineaments and grooves, unlike the planetary-style fossae, are the only impact-induced structural features formed on Lutetia (Thomas et al., 2012; Preusker et al., 2012a), Eros (Prockter et al. 2002; Buczkowski et al., 2008) and Ida (Asphaug et al., 1996).

Consequently, Vesta's place in a unique intermediate category between rocky planets with high gravities and small asteroids with no interior differentiation allowed for the fossae to form. This paper expands upon the link between impact cratering processes and structural features on Vesta by presenting findings of a photogeologic structural mapping study of the Saturnalia Fossae and a variety of other, smaller-scale, second-order structures (maximum width of $<1 \mathrm{~km}$ ), which are distinguished from the Saturnalia Fossae by the use of the general descriptive term 'adjacent structures'. These adjacent structures are sub-classified into minor ridges, grooves and crater chains and are interpreted to form via processes related to impacts of a variety of scales. All the studied structures are located in Vesta's northern hemisphere, primarily in Caparronia and Domitia quadrangles (Fig. 1).

\section{Methods}

\subsection{Data sources: basemaps and ancillary data}

The Vesta science phase of the Dawn mission lasted from May 3rd 2011 to August 26th 2012. During this time data were acquired by the Dawn spacecraft in six stages: (1) Approach, (2) Survey, (3) High Altitude Mapping Orbit 1 (HAMO 1), (4) Low Altitude Mapping Orbit (LAMO), (5) High Altitude Mapping Orbit 2 (HAMO 2) and (6) Departure. Data were collected by Dawn's three instruments: (1) the Framing Camera (FC) (Sierks et al., 2011; Schröder et al., 2013), (2) the Visible and Infrared Spectrometer (VIR) (De Sanctis et al., 2011) and (3) the Gamma Ray and Neutron Detector (GRaND) (Prettyman et al., 2011).

This work mainly uses clear filter FC images and mosaics from HAMO 1 ( $\sim 65 \mathrm{~m} /$ pixel $),$ LAMO $(\sim 20 \mathrm{~m} /$ pixel $)$ and HAMO 2 ( $\sim 65 \mathrm{~m} /$ pixel). The individual quadrangle maps were primarily based on LAMO mosaics of Caparronia and Domitia quadrangles, overlain on HAMO 2 mosaics (Fig. 3a and b). A LAMO mosaic of all the northern quadrangles, overlain on a HAMO 2 mosaic, was also utilized (Fig. 3c) to map the Saturnalia Fossae, in the entire northern hemisphere, and the adjacent structures, in Floronia quadrangle. The LAMO mosaics were overlain on the HAMO 2 mosaics because Vesta's axial tilt caused the northernmost regions of Vesta to be shadowed during LAMO. 

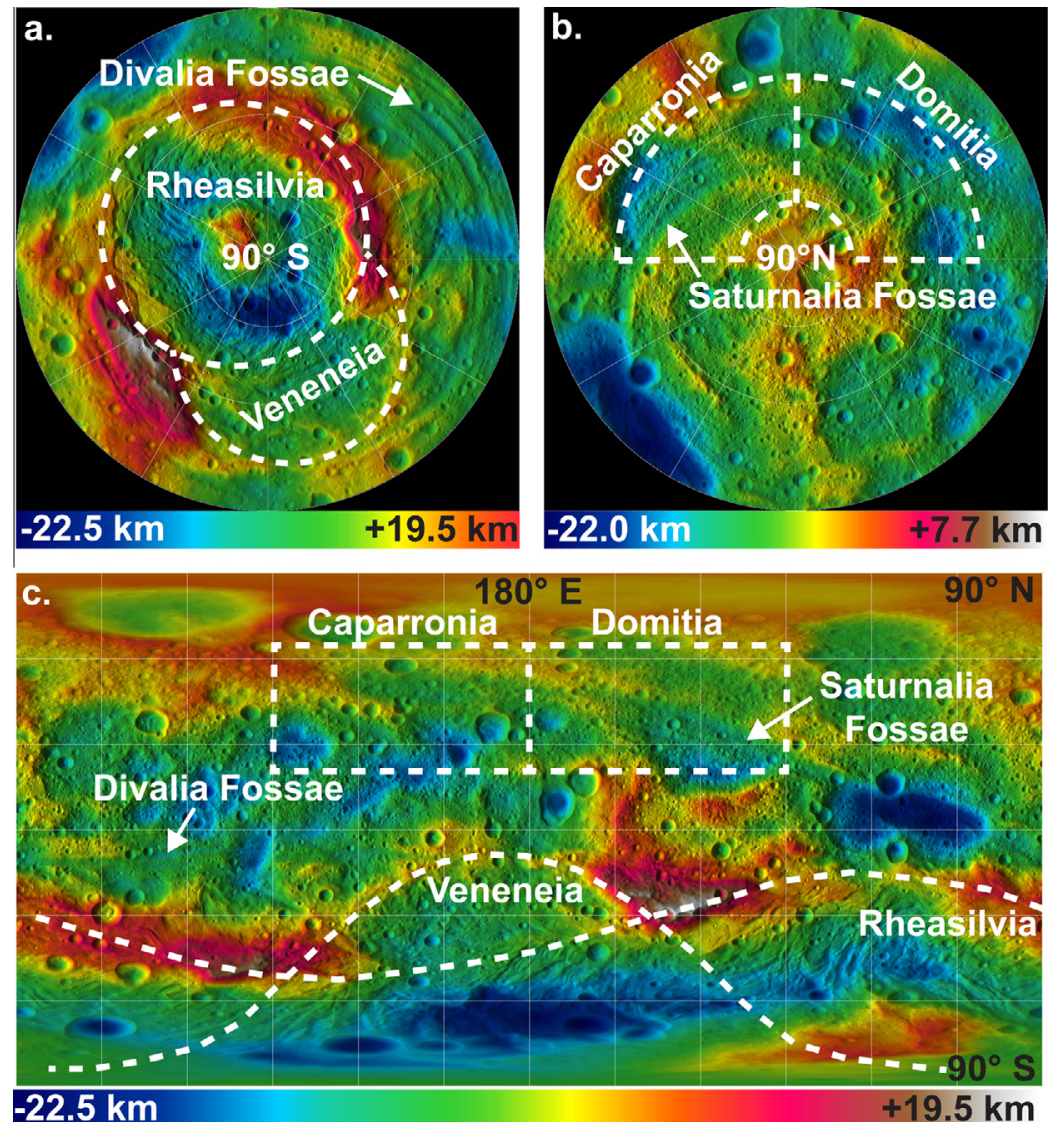

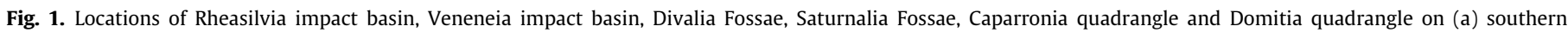
hemisphere, (b) northern hemisphere and (c) whole Vesta topography maps relative to a reference ellipsoid (maps credit: R. Gaskell and D. O’Brien, PSI).

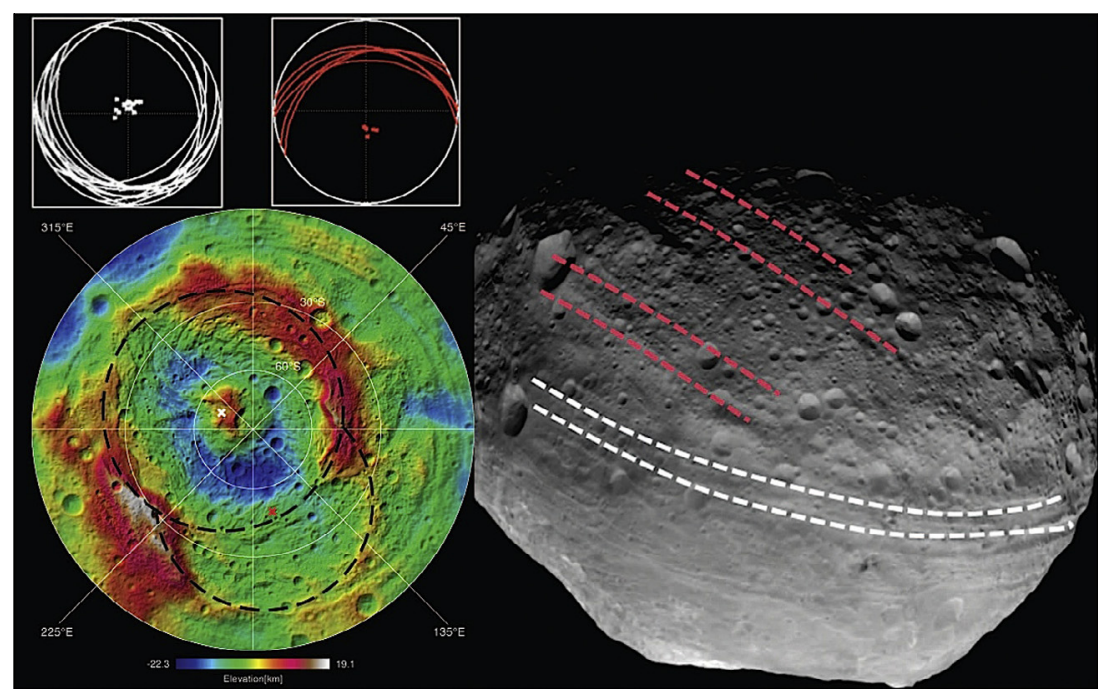

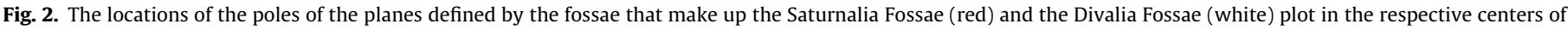

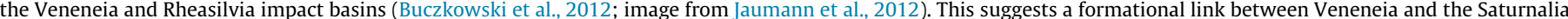

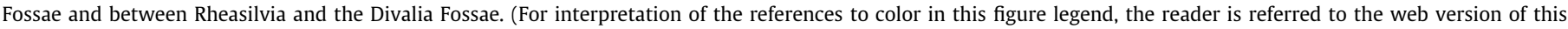
article.)

Photometrically corrected mosaics of Caparronia and Domitia quadrangles were also used in the mapping process. The procedure by which the images were photometrically corrected is outlined in Schröder et al. (submitted for publication). Additionally, topographic data are provided by shape models derived by stereo- photoclinometry (Gaskell, 2012) and stereophotogrammetry (Preusker et al., 2012b) from the FC data, which have a height uncertainty/accuracy of approximately $\leqslant 10 \mathrm{~m}$ (Fig. 3d). Compositional data are provided in the form of hyperspectral images recorded by the VIR instrument, with wavelengths ranging from 

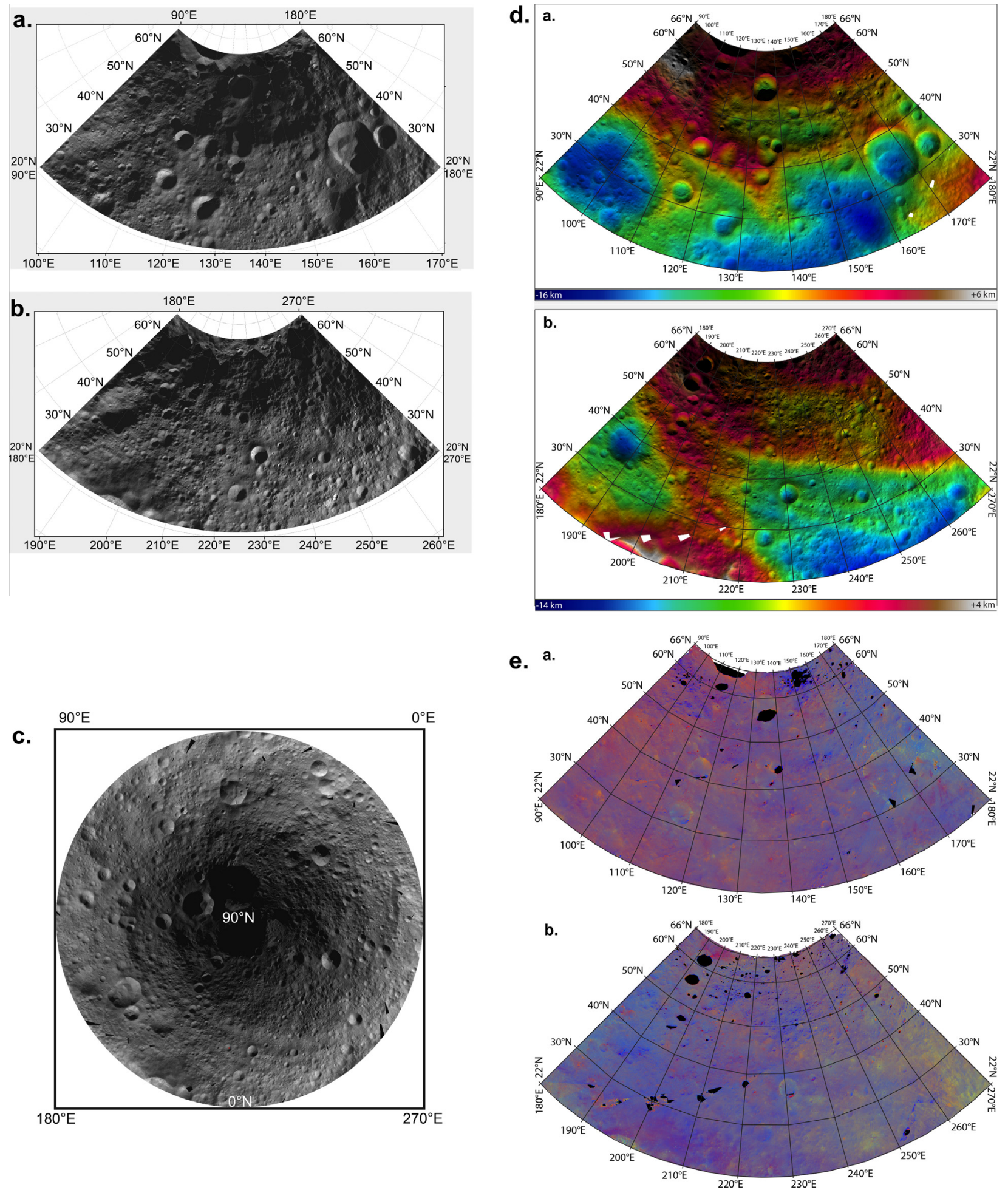

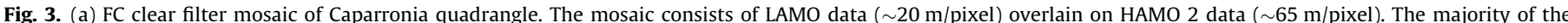

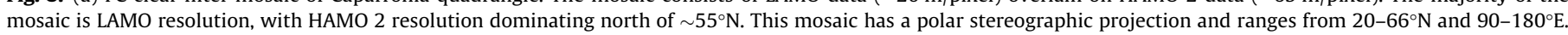

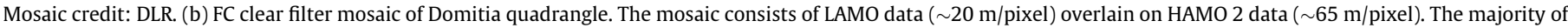

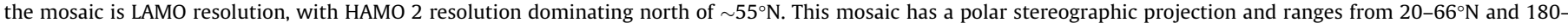

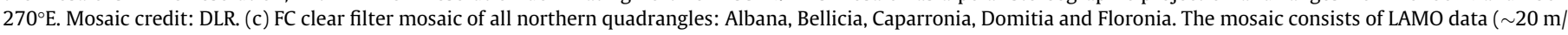

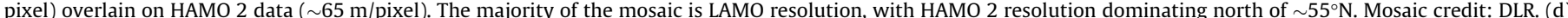

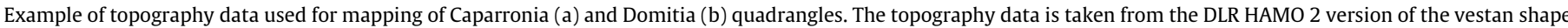

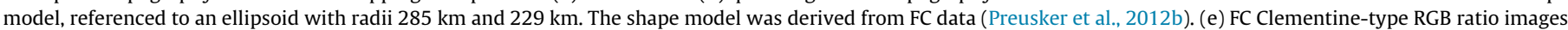

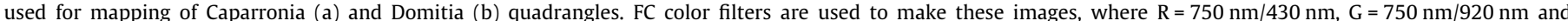

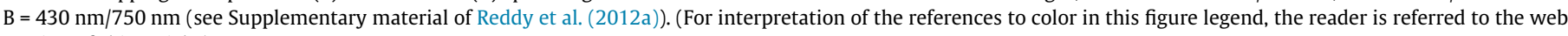
version of this article.) 
near-ultraviolet to mid-infrared $(\sim 0.3-5.0 \mu \mathrm{m})$ (De Sanctis et al., 2011). Compositional data are also provided by the GRaND instrument, which measures the elemental composition of the vestan surface (Prettyman et al., 2011). Further compositional data are provided by the seven color filters of the FC, which cover visible to near-infrared wavelengths (438-965 nm) (Sierks et al., 2011). In particular, Clementine-type RGB ratio images of FC color filters are used, where $R=750 \mathrm{~nm} / 430 \mathrm{~nm}, G=750 \mathrm{~nm} / 920 \mathrm{~nm}$ and $\mathrm{B}=430 \mathrm{~nm} / 750 \mathrm{~nm}$ (Fig. 3e). Calibration and processing procedures for the FC color data and the creation of false color composites are detailed in the Supplementary material of Reddy et al. (2012a) and Schröder et al. (submitted for publication).

\subsection{Mapping approach: techniques and tools}

The surface of Vesta has been divided into three provinces, which are arranged according to latitude: the Saturnalia Fossae Formation in the north, the Divalia Fossae Formation around the equator and the Rheasilvia Formation in the south (Yingst et al., in press). In order to facilitate systematic geologic mapping, the surface of Vesta was divided into 15 quadrangles, each of which was named after a prominent feature in the quadrangle (Roatsch et al., 2012) (Fig. 4). The feature and quadrangle names were chosen from a list of Vestal Virgins, famous Roman women and Roman festivals. The quadrangles are arranged east of the prime meridian, using the Claudia coordinate system that is anchored by Claudia crater (Reddy et al., 2013; Russell et al., 2012). The Dawn science team uses this coordinate system in all publications. The PDS is providing Dawn data in a longitude system that can be acquired from the Claudia longitude by subtracting $150^{\circ}$. Details about this topic are provided in the Introductory paper to this Special Issue (Williams et al., this issue). A team consisting of a lead mapper and mappers from neighboring quadrangles mapped each quadrangle.

Geological mapping was carried out using ESRI ArcMap 10.0 software, which allows the mapping to be georeferenced to the underlying mosaics. Mapping symbols correspond to those recommended for planetary geology features (Federal Geographic Data Committee, 2006). All 15 quadrangles were mapped using ESRI ArcMap 10.0 and further details of the mapping procedure are available in the Introductory paper to this Special Issue (Williams et al., this issue). Furthermore, additional tools were used in this study due to the three-dimensional nature of the structures being investigated. The Small Body Mapping Tool (Kahn et al., 2011) was used to directly map the Saturnalia Fossae onto the shape model of Vesta. JMARS (for Vesta), developed by ASU's Mars Space Flight Facility, was used to obtain profiles across the fossae. Mapping of the fossae in the Small Body Mapping Tool and JMARS (for Vesta) was transferred into ESRI ArcMap 10.0 by visual transcription, using patterns of craters and other morphological features for reference.

\section{Results}

\subsection{Maps}

In accordance with the other papers in this Special Issue, the geological maps of Caparronia quadrangle (Fig. 5a) and Domitia quadrangle (Fig. 5b) contain all of the mapped features apart from craters $<6 \mathrm{~km}$ in diameter. In this paper, versions of the geological maps with craters $<6 \mathrm{~km}$ in diameter are also included (Fig. 6a and b). In these figures the quadrangle maps are overlain on the LAMOHAMO 2 composite quadrangle mosaics. Mapping of the structural features, which consist of the fossae (Fig. 7) and the adjacent structures (Fig. 8) in Caparronia, Domitia and Floronia quadrangles, was conducted on the LAMO-HAMO 2 mosaic of the northern quadrangles.

\subsection{Definition of Map Units (DOMU)}

The map units in Caparronia and Domitia quadrangles are described in the Definition of Map Units, from oldest (stratigraphically lowest) to youngest (stratigraphically highest). The unit symbols use the first letter of each word in the unit name, which are capitalized when appropriate (i.e. for proper nouns).

\subsubsection{Vestalia Terra unit}

4.2.1.1. Observation. The unit symbol is VT and the type area is located at $22^{\circ} \mathrm{N}, 224^{\circ} \mathrm{E}$ (Fig. 9b). This unit is found along the southcentral and southeastern border of Domitia quadrangle. This unit is topographically higher than surrounding units, which is illustrated by a gradational decrease in elevation away from this unit

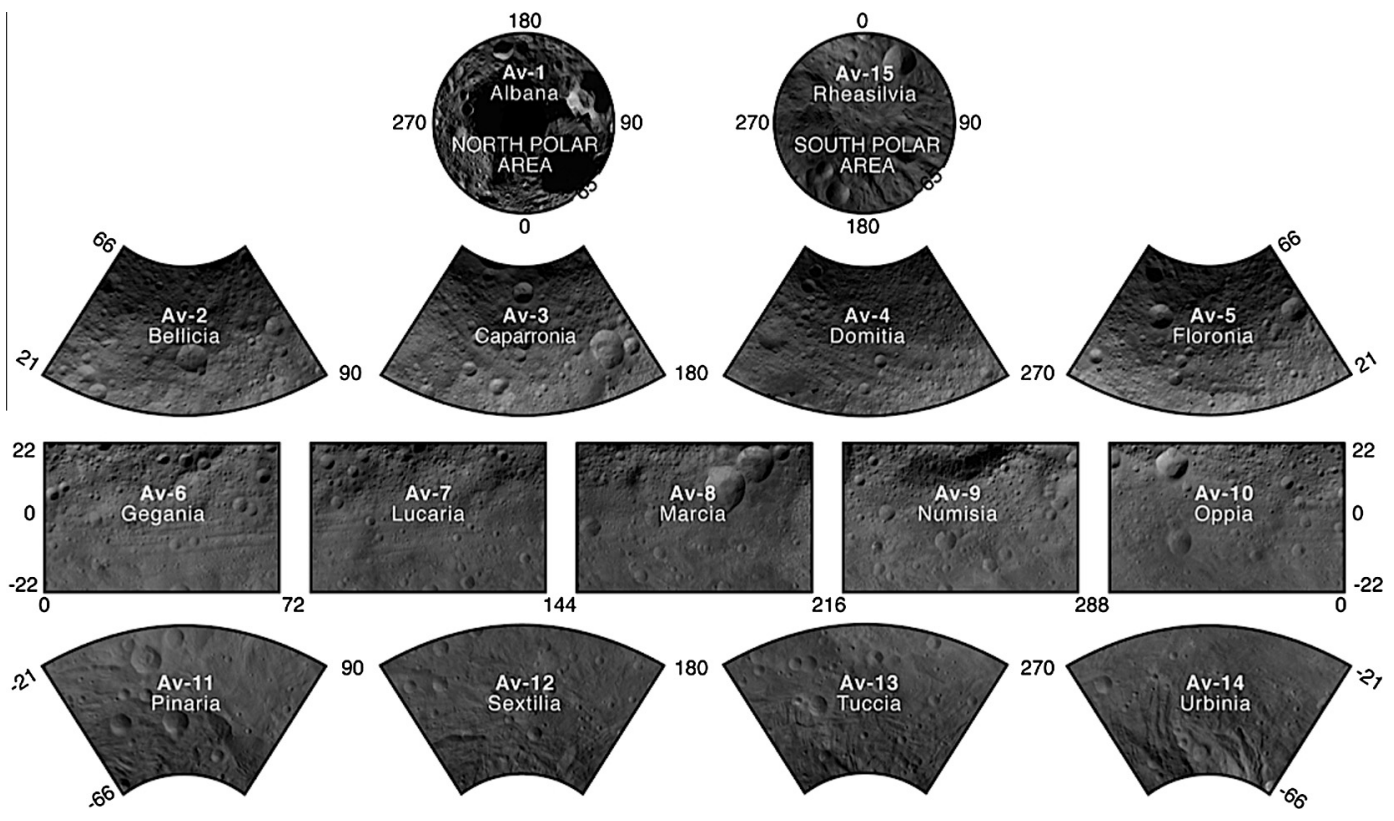

Fig. 4. Schematic atlas of 15 quadrangles that cover the vestan surface (Roatsch et al., 2012). 
a

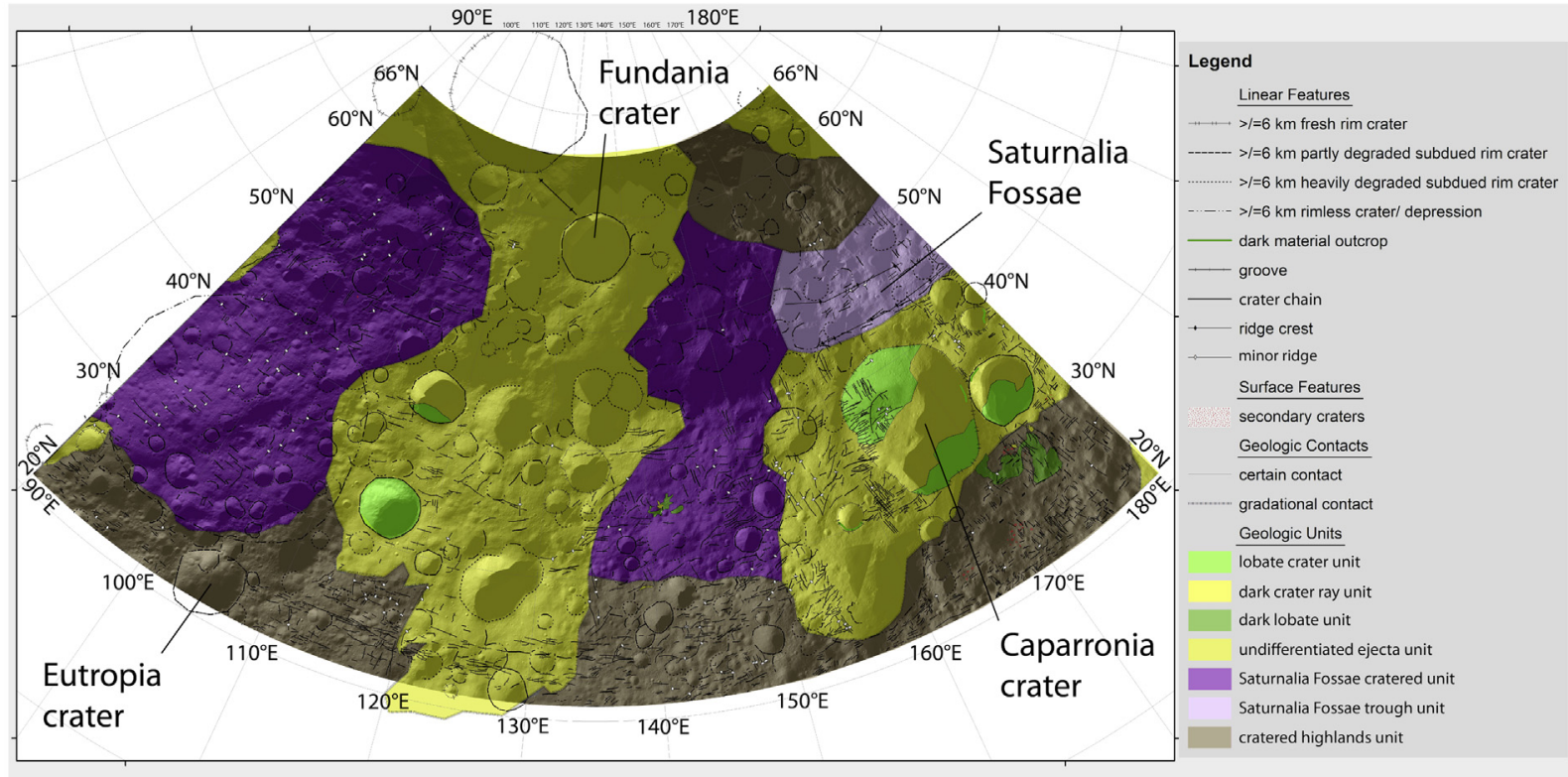

b
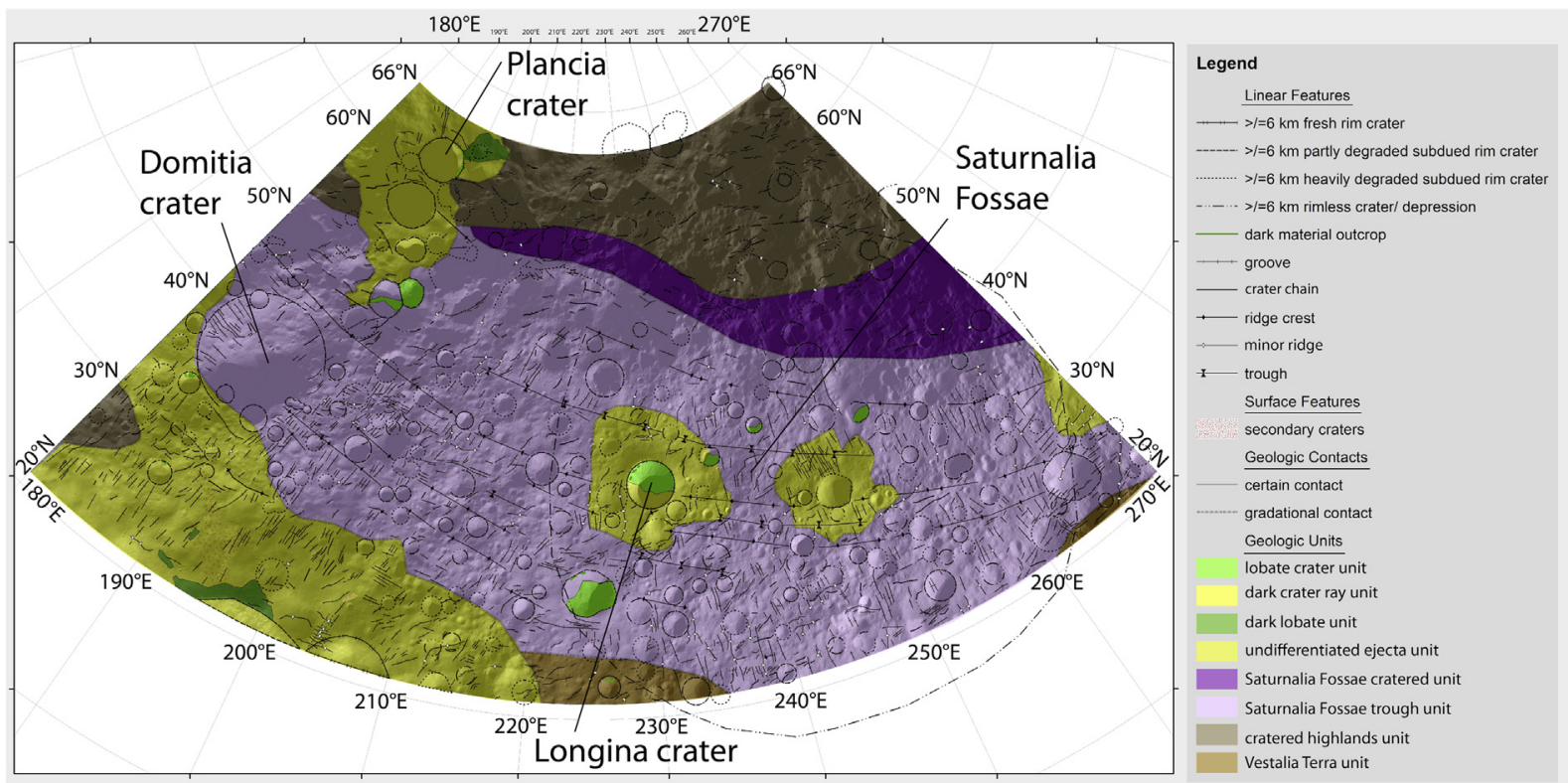

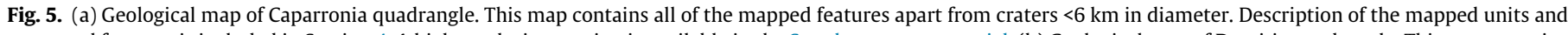

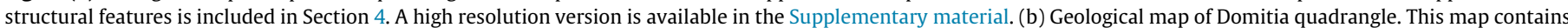

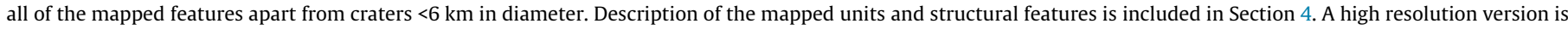
available in the Supplementary material.

in the shape models. This unit contains many impact craters, which have different levels of degradedness. The unit exhibits an albedo that is heterogeneous and intermediate in photometrically corrected FC images. Areas of intermediate albedo are qualitatively defined, when compared by eye in the photometrically corrected images, as regions of albedo that are less dark than distinctly dark regions (discussed in McCord et al., 2012; Reddy et al., 2012b) and less bright than distinctly bright regions (discussed in Zambon et al., in preparation). In Clementine-type FC color ratio images the part of the unit that occurs in Domitia quadrangle has a variety of colors, but the underlying dominant color is violet. The assigned RGB color of this unit in the geologic maps is 168-112-0.

4.2.1.2. Interpretation. The dominant process within this unit is impact cratering. Heterogeneous spectral properties suggest a variety of surface materials, likely excavated by the abundant impact craters in this unit. However, the underlying, dominant violet color of this unit in Clementine-type FC color ratio images suggests that the regolith is dominated by howardite (i.e. a degraded mix of eucrite and diogenite) (Reddy et al., 2012a). This unit and the cratered highlands unit are very similar in the quadrangles studied in this paper, but in quadrangles to the south it is clear that Vestalia Terra is a different unit and takes the form of a plateau (Buczkowski et al., this issue). Stratigraphic relationships, not visible in the quadrangles studied in this paper, suggest that Vestalia Terra is one of the oldest features on Vesta (Buczkowski et al., this issue). Thus, Vestalia Terra is placed at the bottom of the stratigraphic sequence in this paper.

\subsubsection{Cratered highlands unit}

4.2.2.1. Observation. The unit symbol is ch and the type area is located at $25^{\circ} \mathrm{N}, 174^{\circ} \mathrm{E}$ (Fig. 9c). This unit is found along the 
a
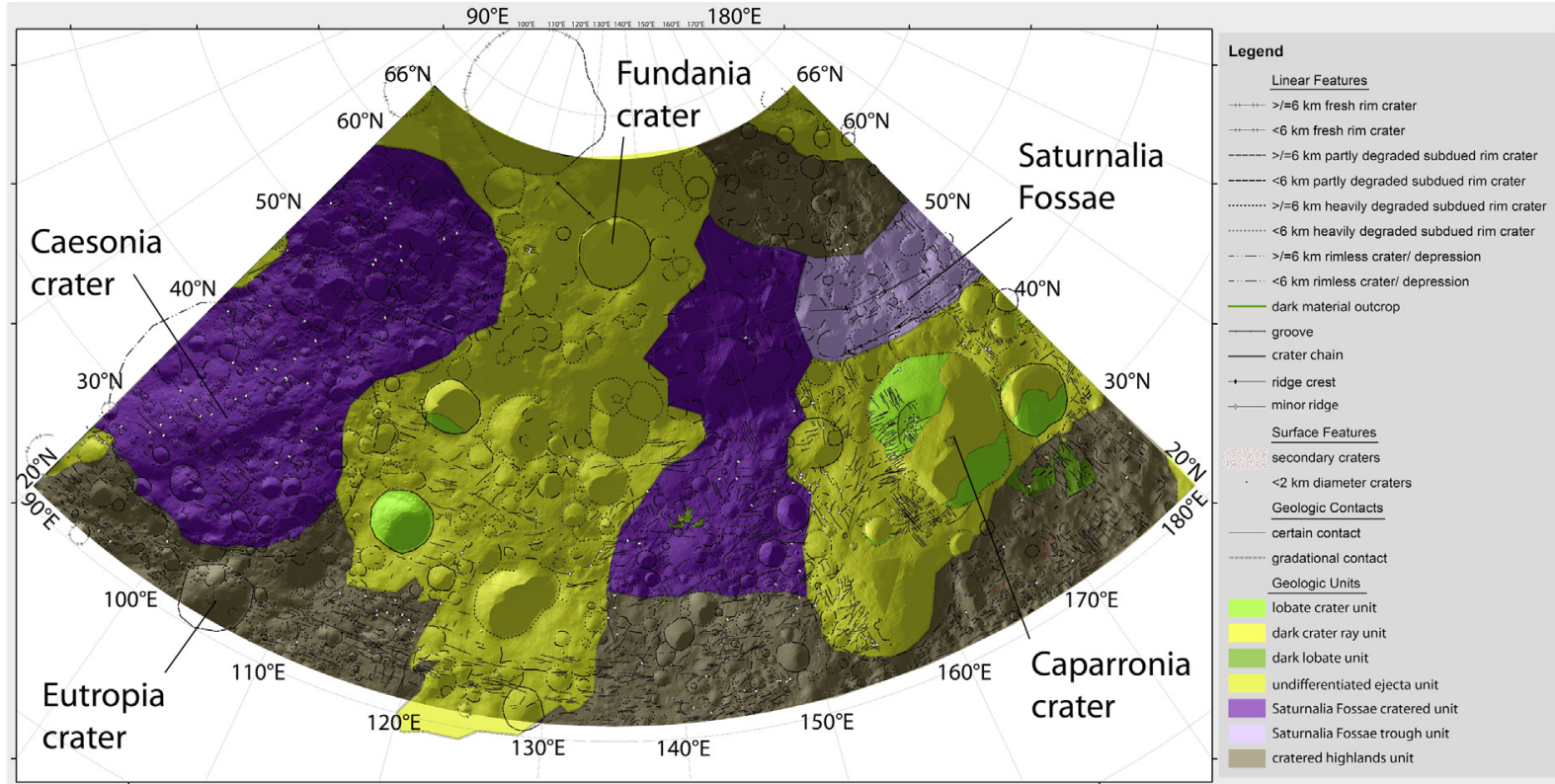

b
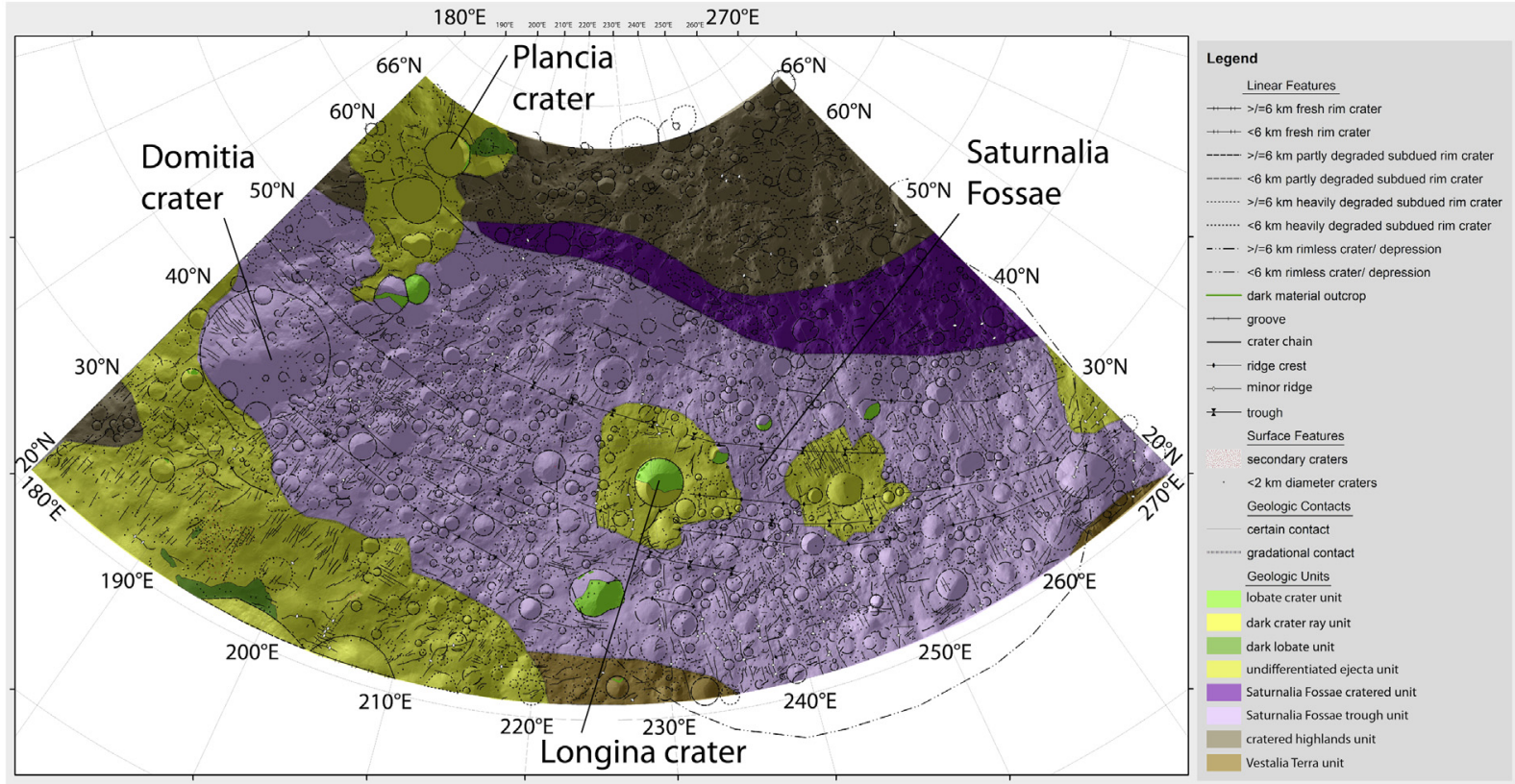

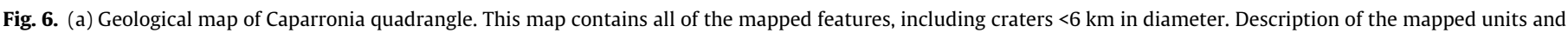

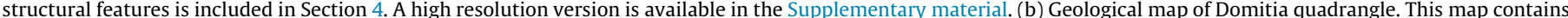

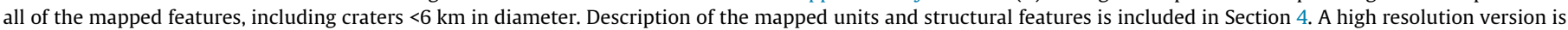
available in the Supplementary material.

southern boundary and in the northeastern corner of Caparronia quadrangle and along the northern boundary and in the southwest corner of Domitia quadrangle. This unit contains many impact craters, which have different levels of degradeness. No clear cross-cutting relationships are identified between this unit and the Saturnalia Fossae Formation in the quadrangles studied in this paper. However, the cratered highlands unit is topographically higher and distinctly more hummocky than the Saturnalia Fossae Formation. All boundaries between this unit and the undifferentiated ejecta unit and Saturnalia Fossae Formation are gradational. The unit exhibits an albedo that is heterogeneous and intermediate in photometrically corrected FC images. In Clementine-type FC color ratio images the unit has a variety of colors, but the underlying dominant color is violet. The assigned RGB color of this unit in the geologic maps is $137-112-68$.
4.2.2.2. Interpretation. This dominant process within this unit is impact cratering. The fossae do not occur in this unit and consequently did not influence its development. When the entire northern hemisphere is taken into account, this unit is identified as being stratigraphically older than the Saturnalia Fossae Formation (Ruesch et al., this issue). Heterogeneous spectral properties suggest a variety of surface materials, likely excavated by the abundant impact craters in this unit. However, the underlying, dominant violet color of this unit in Clementine-type FC color ratio images suggests that the regolith is dominated by howardite (i.e. a degraded mix of eucrite and diogenite) (Reddy et al., 2012a).

\subsubsection{Saturnalia Fossae Formation}

The Saturnalia Fossae Formation was originally identified as one of Vesta's formations in the global mapping paper 


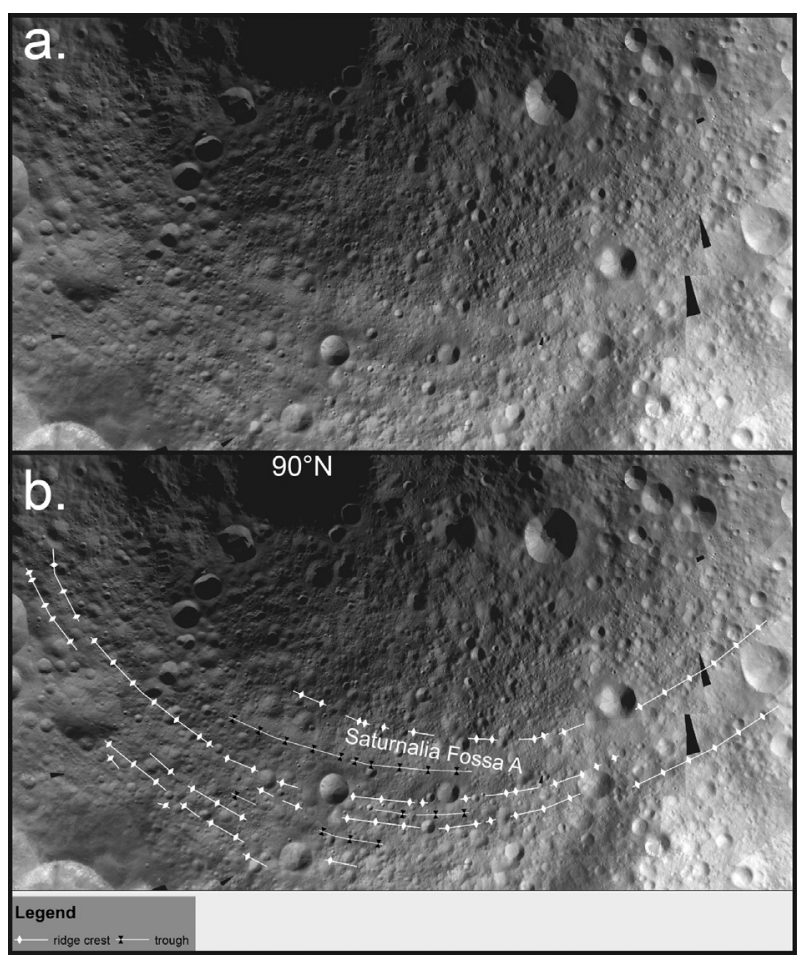

Fig. 7. Unmapped (a) and mapped (b) area of the northern hemisphere in which the Saturnalia Fossae are located. The ridges delineate the edges of the fossae and the troughs delineate the approximate central axes of particularly deep fossae.

(Yingst et al., in press). In Caparronia and Domitia quadrangles the Saturnalia Fossae Formation has been divided into two sub-divisions, based on the presence or absence of the Saturnalia Fossae: the Saturnalia Fossae trough unit contains the Saturnalia Fossae and the Saturnalia Fossae cratered unit does not contain the Saturnalia Fossae. No relative age difference is identified between the two sub-divisions. Both are heavily cratered and, as a part of the Saturnalia Fossae Formation, have the highest crater density of Vesta's formations (Marchi et al., 2012).

\subsubsection{Saturnalia Fossae trough unit.}

4.2.3.1.1. Observation. The unit symbol is SFt and the type area is located at $45^{\circ} \mathrm{N}, 215^{\circ} \mathrm{E}$ (Fig. 9d). This unit is dominant in Domitia quadrangle and is stratigraphically higher than the Vestalia Terra unit. No clear cross-cutting relationships are identified between this unit and the cratered highlands unit in the quadrangles studied in this paper. This unit contains, and is named after, the Saturnalia Fossae. The unit exhibits an albedo that is heterogeneous and intermediate in photometrically corrected FC images. In Clementine-type FC color ratio images the unit has a variety of colors, but the underlying dominant color is violet. The assigned RGB color of this unit in the geologic maps is 232-190-255.

4.2.3.1.2. Interpretation. The dominant process in this unit is the formation of the Saturnalia Fossae, which is discussed in Section 4.3.1. When the entire northern hemisphere is taken into account, this unit is identified as being stratigraphically younger than the cratered highlands unit (Ruesch et al., this issue). Heterogeneous spectral properties suggest a variety of surface materials, likely excavated by the abundant impact craters in this unit. However, the underlying, dominant violet color of this unit in Clementine-type FC color ratio images suggests that the regolith is dominated by howardite (i.e. a degraded mix of eucrite and diogenite) (Reddy et al., 2012a).

\subsubsection{Saturnalia Fossae cratered unit.}

4.2.3.2.1. Observation. The unit symbol is SFc and the type area is located at $40^{\circ} \mathrm{N}, 101^{\circ} \mathrm{E}$ (Fig. 9e). This unit is dominant in Caparronia quadrangle. This unit contains many impact craters, which have different levels of degradation. No clear cross-cutting relationships are identified between this unit and the cratered highlands unit in the quadrangles studied in this paper. This unit does not contain the Saturnalia Fossae. The unit exhibits an albedo that is heterogeneous and intermediate in photometrically corrected FC images. In

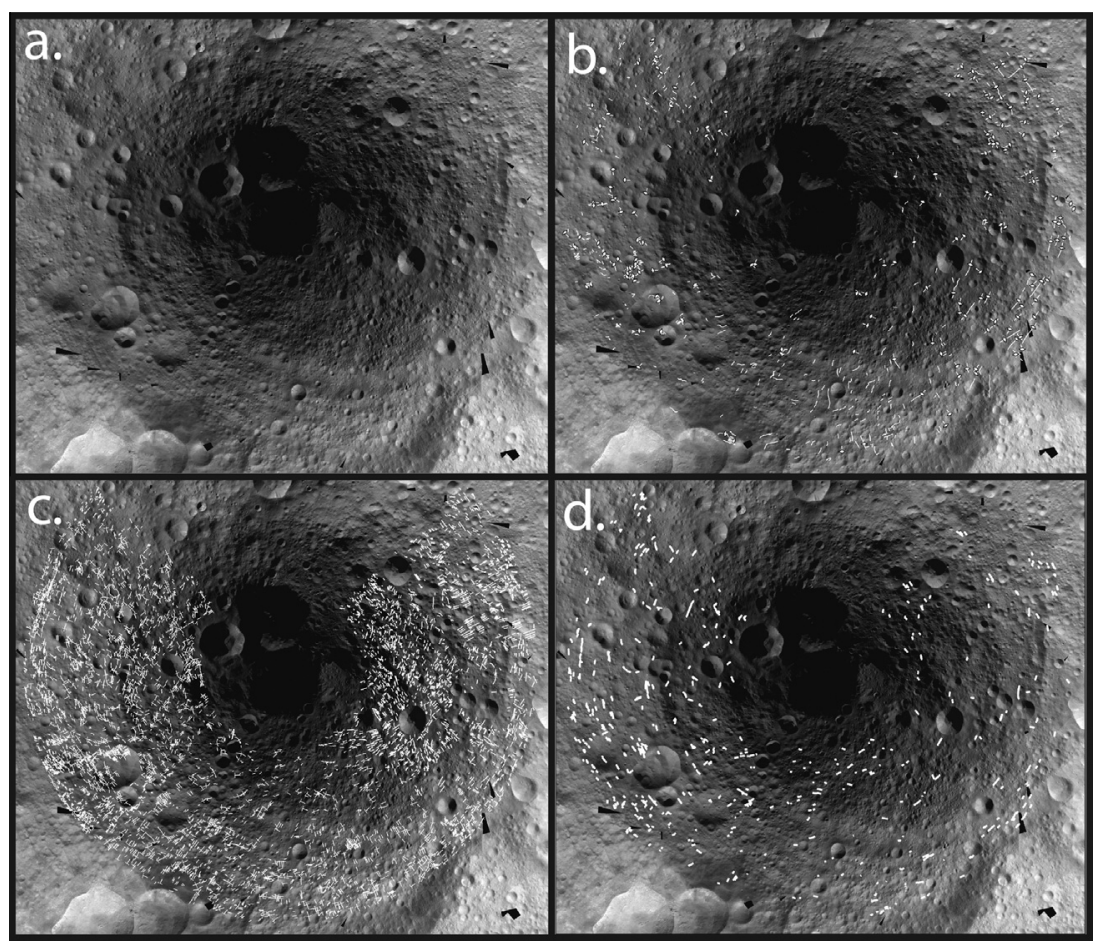

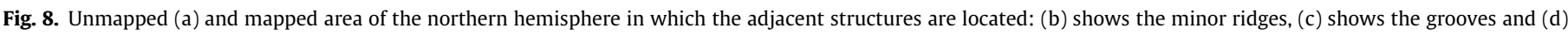
shows the crater chains. 


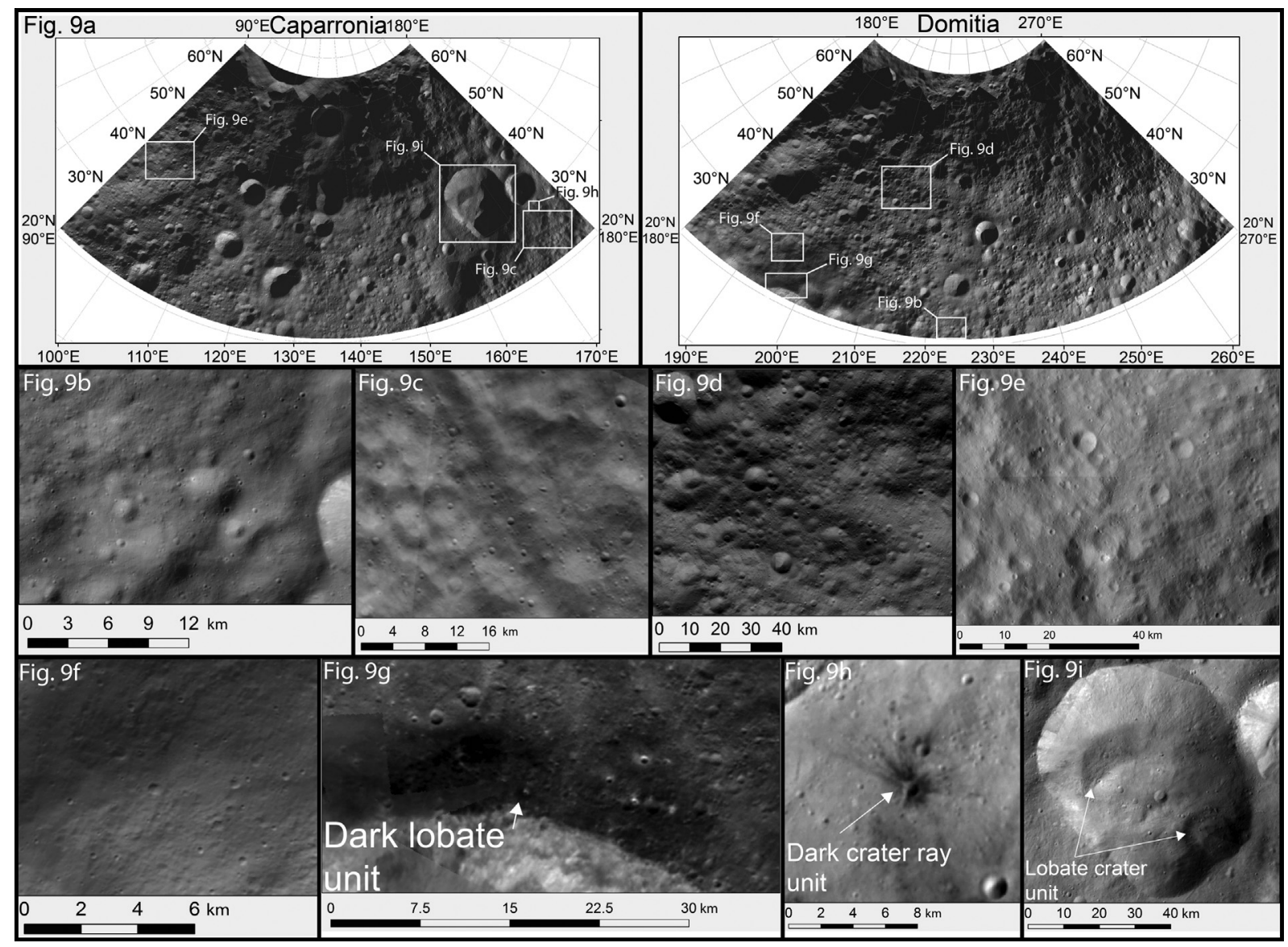

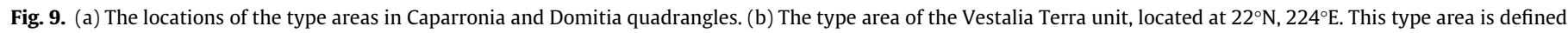

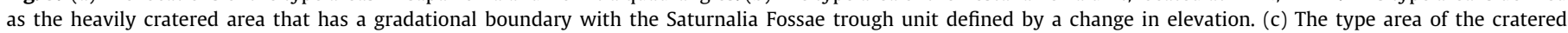

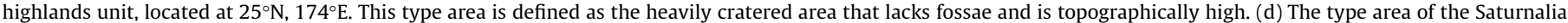

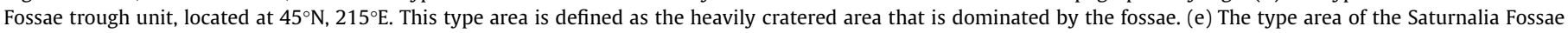

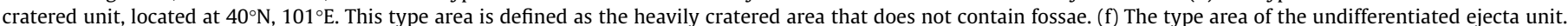

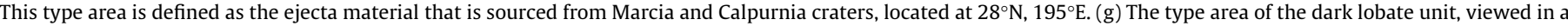

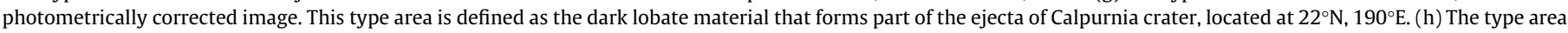

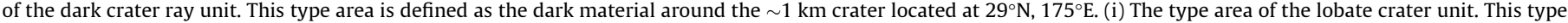
area is defined as the mass wasting deposit within Caparronia crater, located at $37^{\circ} \mathrm{N}, 165^{\circ} \mathrm{E}$.

Clementine-type FC color ratio images the unit has a variety of colors, but the underlying dominant color is violet. The assigned RGB color of this unit in the geologic maps is $132-0-168$.

4.2.3.2.2. Interpretation. Since the Saturnalia Fossae do not occur in this unit, the dominant process is impact cratering. When the entire northern hemisphere is taken into account, this unit is identified as being stratigraphically younger than the cratered highlands unit (Ruesch et al., this issue). Heterogeneous spectral properties suggest a variety of surface materials, likely excavated by the abundant impact craters in this unit. However, the underlying, dominant violet color of this unit in Clementine-type FC color ratio images suggests that the regolith is dominated by howardite (i.e. a degraded mix of eucrite and diogenite) (Reddy et al., 2012a).

\subsubsection{Undifferentiated ejecta unit}

4.2.4.1. Observation. The unit symbol is ue and the type area is located at $28^{\circ} \mathrm{N}, 195^{\circ} \mathrm{E}$ (Fig. 9f). This unit extends asymmetrically from large, well-defined craters that are approximately centrally located within the unit. The unit is observed to cross-cut and has a smoother surface with fewer craters than the Saturnalia Fossae trough unit, the Saturnalia Fossae cratered unit, the cratered highlands unit and the Vestalia Terra unit. The unit contains hummocky, sinuous ridges. The edge is curvilinear and can be defined by a break in topography to the underlying units. However, generally these boundaries are gradational. The unit exhibits an albedo that is heterogeneous and intermediate in photometrically corrected FC images. In Clementine-type FC color ratio images the unit has a variety of colors, but the underlying dominant color is violet. The assigned RGB color of this unit in the geologic maps is 230-230-0.

4.2.4.2. Interpretation. Due to the location of the ejecta and the similar levels of freshness between the ejecta and the centrally located craters, it is likely that material making up the unit was ejected by the impact that formed the centrally located craters. The cross-cutting relationships and the observation that this unit contains a smaller number of craters than the Saturnalia Fossae trough unit, the Saturnalia Fossae cratered unit, the cratered highlands unit and the Vestalia Terra unit result in this unit being placed stratigraphically above the aforementioned units. The underlying, dominant violet color of this unit in Clementine-type FC color ratio images suggests that the regolith is dominated by howardite (i.e. a degraded mix of eucrite and diogenite) (Reddy et al., 2012a).

\subsubsection{Dark lobate unit}

4.2.5.1. Observation. The unit symbol is $\mathrm{dl}$ and the type area is located at $22^{\circ} \mathrm{N}, 190^{\circ} \mathrm{E}$ (Fig. $9 \mathrm{~g}$ ). This unit extends downslope from crater rims and is observed to cross-cut the undifferentiated ejecta 
unit, Saturnalia Fossae cratered unit and cratered highlands unit. The edges are lobate and the surface is generally smooth. The unit has a greater extent and is more diffuse than the dark crater ray unit. This unit does not have a noticeably different distribution of small craters when compared to the undifferentiated crater unit. The unit exhibits a distinctive low albedo in photometrically corrected FC images and a dark violet color in Clementine-type FC color ratio images. The assigned RGB color of this unit in the geologic maps is $56-168-0$.

4.2.5.2. Interpretation. The observation that this unit extends downslope from crater rims suggests that it is material ejected during the crater-forming impact. The cross-cutting relationships with the undifferentiated ejecta unit, Saturnalia Fossae cratered unit and cratered highlands unit result in this unit being placed stratigraphically above the aforementioned units. Other studies have shown dark material, such as this unit, derives from carbonaceous chondrite impacts (McCord et al., 2012; Reddy et al., 2012b). This carbonaceous chondrite dark material commonly has a dark violet color in Clementine-type FC color ratio images (Reddy et al., 2012a).

\subsubsection{Dark crater ray unit}

4.2.6.1. Observation. The unit symbol is dcr and the type area is located at $29^{\circ} \mathrm{N}, 175^{\circ} \mathrm{E}$ (Fig. 9h). This unit is located around certain impact craters and extends for greater than one crater diameter from the crater rim. The unit cross-cuts each of the dark lobate unit, undifferentiated ejecta unit, Saturnalia Fossae cratered unit and cratered highlands unit. This unit forms linear streaks or rays of varying lengths that are oriented sub-perpendicular to crater rims and are asymmetrically distributed around craters. The unit exhibits a distinctive low albedo in photometrically corrected FC images and the unit is dominated by a dark violet color in Clementine-type FC color ratio images. The assigned RGB color of this unit in the geologic maps is 255-255-0.

4.2.6.2. Interpretation. The unit is interpreted to be material ejected from the impact crater that it surrounds because the unit is always located around impact craters and the rays radiate away from the impact craters. The cross-cutting relationships with the dark lobate unit, undifferentiated ejecta unit, Saturnalia Fossae cratered unit and cratered highlands unit result in this unit being placed stratigraphically above the aforementioned units. Other studies have shown dark material, such as this unit, derives from carbonaceous chondrite impacts (McCord et al., 2012; Reddy et al., 2012b). This carbonaceous chondrite dark material commonly has a dark violet color in Clementine-type FC color ratio images (Reddy et al., 2012a).

\subsubsection{Lobate crater unit}

4.2.7.1. Observation. The unit symbol is lc and the type area is located at $37^{\circ} \mathrm{N}, 165^{\circ} \mathrm{E}$, within Caparronia crater (Fig. 9i). This unit is located on the interior slopes of fresh rim and partly degraded subdued rim craters and originates from the crater rim and partly or completely fills the crater. The unit is observed to cross-cut the undifferentiated ejecta unit and the Saturnalia Fossae trough unit. The lobate crater unit forms lobate deposits that display lateral and/or transverse curvilinear ridges and curvilinear or scalloped edges. Hummocky surface morphologies result from the irregular distribution of material. These are interspersed with areas of smoother material. Small craters, up to a few hundred meters in diameter, occur on the surface. The smallest craters discernible are $\sim 40-50 \mathrm{~m}$ in diameter because the resolution of the LAMO images is $\sim 20 \mathrm{~m} /$ pixel. In photometrically corrected FC images the albedo is intermediate, but is brighter along crater rims. In Clementine-type FC color ratio images the unit has a yellow color, particularly along crater rims, but the underlying dominant color is violet. The assigned RGB color of this unit in the geologic maps is 85-255-0.

4.2.7.2. Interpretation. Since this unit is located on the interior slopes and floors of craters and originates from their rims, this unit is interpreted to form after slope failure results in slide, slump or flow of regolith, possibility initiated during or after crater formation. This interpretation is consistent with the lobate form of the unit and the lateral and/or transverse curvilinear ridges and curvilinear or scalloped edges, which are all morphologies consistent with slide, slump or flow of material (e.g. Varnes, 1978). The underlying, dominant violet color of this unit in Clementine-type FC color ratio images suggests that the regolith is dominated by howardite (i.e. a degraded mix of eucrite and diogenite) (Reddy et al., 2012a). However, the brighter, yellow crater rims are indicative of the howardite being mixed with fresher material that slid, slumped or flowed from the crater rim (Pieters et al., 2012). Possible initiation mechanisms for this slope failure include steepening of slopes exceeding the angle of repose and seismic shaking induced by impacts.

\subsection{Observation and interpretation of structures}

\subsubsection{Saturnalia Fossae}

4.3.1.1. Observation. The Saturnalia Fossae are the principal, firstorder structural feature in Vesta's northern quadrangles. The edges of the fossae are mapped as ridge crests with solid diamonds and the type area is located at $37^{\circ} \mathrm{N}, 242^{\circ} \mathrm{E}$ (Fig. 10). Sometimes fragments of the ridges are smoothed out by later processes (see Section 4.3.1.2), which results in them not always being visible as sharply defined features in the topographic data. Two sub-parallel ridge crests make up each fossae. Parts of the centers of the fossae are mapped as troughs. The full extent of the fossae is shown in Fig. 7.

The Saturnalia Fossae are mostly located in Domitia quadrangle, but also continue into Caparronia and Floronia quadrangles. These features are within the Saturnalia Fossae Formation, specifically within the Saturnalia Fossae trough unit. The undifferentiated ejecta unit (see Section 4.2.4) and lobate crater unit (see Section 4.2.7) overlie or cross-cut the fossae. There are a maximum of 5 fossae within the group, of which Saturnalia Fossa A is the dominant structure. Saturnalia Fossa A is the largest of the fossae, with a maximum width of $\sim 43 \mathrm{~km}$.

An estimate of the minimum thickness of the regolith in the area around the Saturnalia Fossae is found by using the depth of nearby Caparronia crater. Caparronia is a fresh, $\sim 54 \mathrm{~km}$ diameter crater that is located south of the Saturnalia Fossae at $36^{\circ} \mathrm{N}$, $167^{\circ} \mathrm{E}$. A deficiency of large boulders and slump blocks indicate that this crater does not excavate appreciable amounts of coherent material. Using a depth to diameter value of 0.18 (Vincent et al., 2012) gives the depth of Caparronia to be $\sim 10 \mathrm{~km}$, which is also the minimum regolith depth.

Profiles across representative transects of the fossae were made using JMARS (for Vesta) (Fig. 11a and b). Before interpretation the profiles were rotated (Fig. 11c and d). In cross section Saturnalia Fossa $\mathrm{A}$ is an approximately symmetrical rounded depression, while the other fossae (B-E) are generally more asymmetric rounded depressions (Fig. 11a and b). The depth of Saturnalia Fossa A (maximum depth of $\sim 4.5 \mathrm{~km}$ ) is greater than the other fossae (BE), which have a maximum depth of $\sim 2 \mathrm{~km}$.

A rose diagram displaying the orientations of the ridges (Fig. 12a) displays that the mean direction is $168^{\circ} / 348^{\circ}$. However, this mean direction is in a coordinate system that cannot be easily related to the map view. Hence, the orientations of the ridges are also plotted in rose diagrams that can be more easily related to 


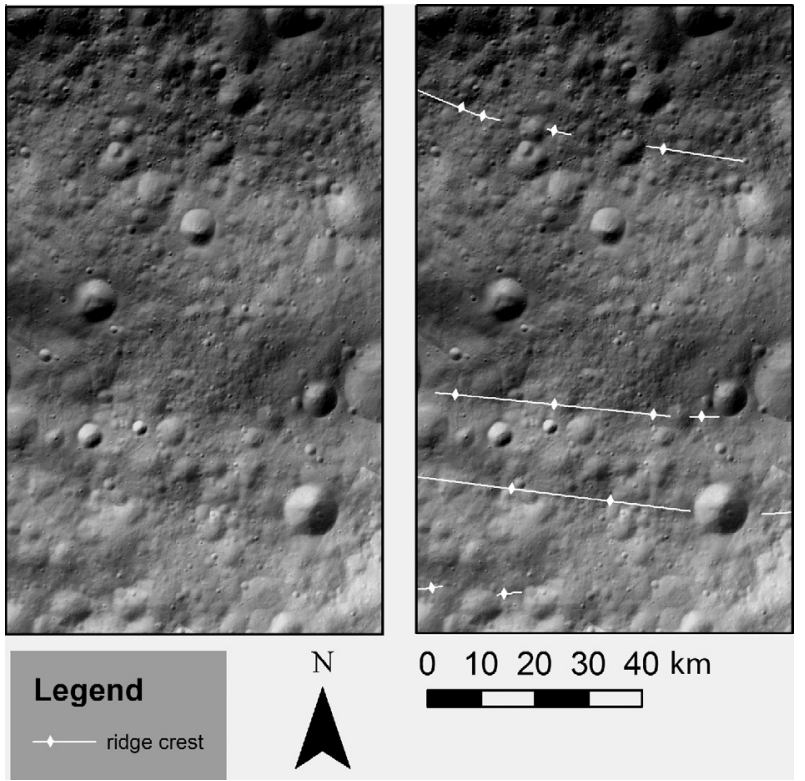

Fig. 10. Unmapped and mapped versions of the type area of the Saturnalia Fossae. In this image Saturnalia Fossa A is the wider fossa and Saturnalia Fossa B is the narrower fossa. This type area is located at $37^{\circ} \mathrm{N}, 242^{\circ} \mathrm{E}$.

map view (with a simple cylindrical projection). In this view the ridges have a direction of ESE-WNW (Fig. 12b).

4.3.1.2. Interpretation. The tight clustering of the ridges on the Rose diagram (Fig. 12a and b) suggests that the fossae have a related formation mechanism. It has been previously suggested that since Saturnalia Fossa $A$ is made up of two sub-parallel ridge crests in plan view and is symmetrical with a somewhat rounded floor in profile view, it resembles a graben structure (Buczkowski et al., 2012). The thick regolith deposit in this area, $\leqslant 10 \mathrm{~km}$, is interpreted to have modified the morphology of Saturnalia Fossa A from that of an unmodified, flat-floored graben to that of a graben with a somewhat rounded floor. Accumulation of ejecta units such as the undifferentiated ejecta unit and lobate crater unit on top of the fossae is also thought to have rounded and/or smoothed the profile of the fossae.

In the interpreted profiles (Fig. 11c and d), Saturnalia Fossa A is the deepest fossae and is symmetrical in profile, which is interpreted to be due to the presence of two large, symmetrical normal faults on either side, which form a graben. In interpreted profile 1 (Fig. 11c), fossae B-C are asymmetric in profile and significantly shallower than Saturnalia Fossa A and are consequently interpreted to be half grabens. It is likely that they are formed by synthetic faults that may connect to the southernmost Saturnalia Fossa A fault at depth. Synthetic faults are minor faults that have the same sense of displacement as the main fault. They form because faults are not one isolated plane of discontinuity, but are bounded by a damage zone in which smaller, secondary faults can form (Twiss and Moores, 2007). In interpreted profile 2 (Fig. 11d), fossae D and E, which also have asymmetric profiles, become apparent. These asymmetric profiles are also interpreted to be due to fossae $\mathrm{D}$ and $\mathrm{E}$ being half grabens that are also formed by synthetic faults. The lack of mapped structures to the north of Saturnalia Fossa A in the profiles means that no interpretations are made in this area. Note that the large thickness of regolith in the region, $\leqslant 10 \mathrm{~km}$, is interpreted to result in the Saturnalia Fossae normal faults not cropping out at Vesta's surface. Thus, these faults are likely blind faults and the ridges that delineate the edges of the fossae are likely regolith piled up on top of the normal faults rather than the exposed normal fault scarps. The regolith on top of the normal faults is shown in the interpreted profiles as the pale gray layer (Fig. 11c and d).

\subsubsection{Minor ridges}

4.3.2.1. Observation. The minor ridges are positive topography features that are mapped as ridge crests with open diamonds. For classification purposes, the general descriptive term 'minor ridges' characterizes second-order ridges that are not part of the Saturnalia Fossae and are an order of magnitude smaller, since minor ridges have a maximum width of $<1 \mathrm{~km}$ and Saturnalia Fossa A has a maximum width of $\sim 43 \mathrm{~km}$. The type area is located at $40^{\circ} \mathrm{N}, 203^{\circ} \mathrm{E}$ (Fig. 13). The minor ridges are mapped in detail in Caparronia, Domitia and Floronia quadrangles (Fig. 8b).

Minor ridges range in length from $\sim 2 \mathrm{~km}$ to $\sim 25 \mathrm{~km}$ and range in morphology from linear to curvilinear. Individual minor ridges are not resolved in profile. Consequently, their depth cannot be measured and they must be significantly shallower than the fossae. The minor ridges are generally discrete and only coalesce together occasionally. Some minor ridges are observed to cross-cut impact craters (Fig. 13).

A rose diagram displaying the orientations of the minor ridges (Fig. 12c) shows that the mean direction is $37^{\circ} / 217^{\circ}$. In map view, using a simple cylindrical projection, this corresponds to a direction of NE-SW (Fig. 12d). The orientations of the minor ridges are more spread out than those of the other structures but they can be divided into two dominant groupings of orientations. One group is approximately aligned $\mathrm{E}-\mathrm{W}$, which is approximately parallel to the regional slope in the area (Fig. 12d). The second group is roughly aligned NE-SW and $\mathrm{N}-\mathrm{S}$, which is not approximately parallel to the regional slope (Fig. 12d).

4.3.2.2. Interpretation. The two groupings of minor ridges are interpreted to have two different formation mechanisms, which are discussed in this section. The group of minor ridges aligned approximately parallel to regional slope, E-W, may be accumulations of regolith that piled up as the material flowed under the control of the regional slope.

However, this formation mechanism cannot be invoked for the minor ridges approximately aligned NE-SW and N-S. The previously described morphology of the minor ridges is of curvilinear scarps that closely resemble wrinkle ridges/thrust scarps observed in LROC images of the Moon (e.g., Watters et al., 2010), in MESSENGER images of Mercury (e.g. Watters et al., 2009) and on Mars (e.g. Golombek et al., 2001). Evidence that sub-surface thrusting forms wrinkle ridge morphologies is observed in terrestrial analogs to wrinkle ridges, which are formed over sub-surface thrust faults (Plescia and Golombek, 1986). The observation that some minor ridges cross-cut impact craters (Fig. 13) is interpreted to be evidence that the minor ridges are wrinkle ridges that are thrust over impact craters under the control of sub-surface thrust faults.

\subsubsection{Grooves and crater chains}

4.3.3.1. Observation. The grooves are negative topography features that are mapped using a solid line with orthogonal ticks. The type area is located at $23^{\circ} \mathrm{N}, 117^{\circ} \mathrm{E}$ (Fig. 14). The crater chains are also negative topography features and are mapped using a solid line. The type area is located at $30^{\circ} \mathrm{N}, 173^{\circ} \mathrm{E}$ (Fig. 15). The grooves and crater chains are also mapped in detail in Caparronia, Domitia and Floronia quadrangles (Fig. $8 \mathrm{c}$ and d).

The grooves are the most prevalent of the second-order adjacent structures in Vesta's northern quadrangles. The grooves range in length from $\sim 3 \mathrm{~km}$ to $\sim 25 \mathrm{~km}$ and range in morphology from linear to curvilinear. The crater chains are also second-order adjacent structures, range in length from $\sim 1 \mathrm{~km}$ to $\sim 25 \mathrm{~km}$ and range in morphology from linear to curvilinear. The individual grooves 

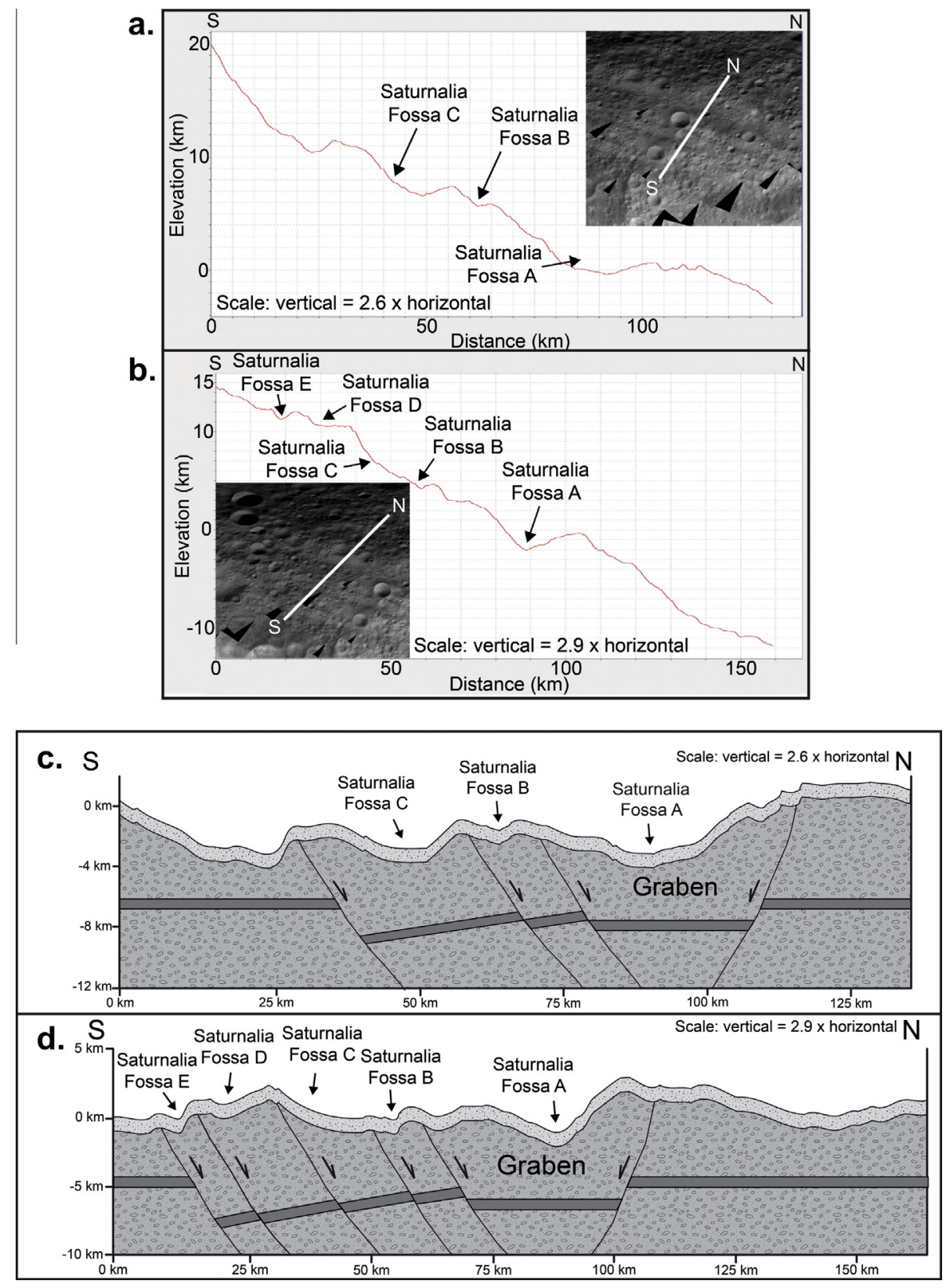

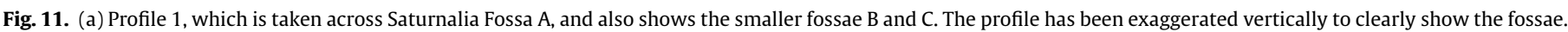

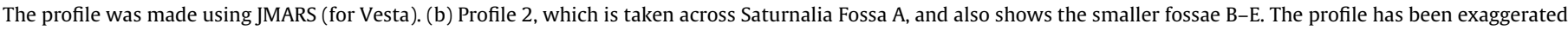

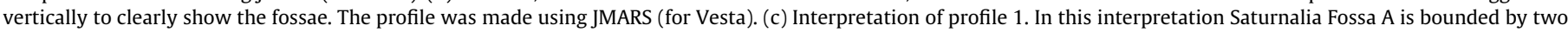

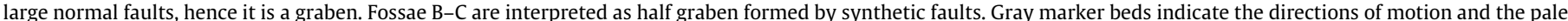

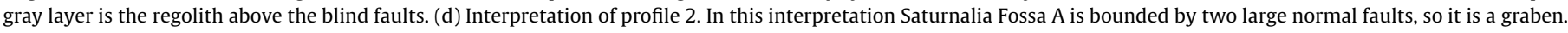

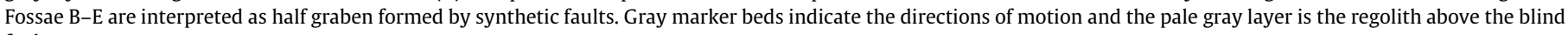
faults.

and crater chains are not resolved in profile. Consequently, their depth cannot be measured and they must be significantly shallower than the fossae. Some grooves or crater chains coalesce together, but they are generally discrete features.

A rose diagram displaying the orientations of the grooves (Fig. 12e) shows that the mean direction is $13^{\circ} / 193^{\circ}$. In map view, with a simple cylindrical projection, this corresponds to a direction of E-W (Fig. 12f). A rose diagram for the orientations of the crater chains (Fig. 12g) shows that the mean direction is $8^{\circ} / 188^{\circ}$. In map view, with a simple cylindrical projection, this corresponds to a direction of E-W (Fig. 12h).
Sometimes, grooves and crater chains are orientated radially around an impact crater. At $27^{\circ} \mathrm{N}, 199^{\circ} \mathrm{E}$, there are NNE-SSW trending grooves and crater chains (Fig. 16) that form an approximately radial pattern to Calpurnia crater. Similarly radial grooves are located from $\sim 21^{\circ} \mathrm{N}$ to $\sim 43^{\circ} \mathrm{N}$ and $\sim 180^{\circ} \mathrm{E}$ to $\sim 220^{\circ} \mathrm{E}$, around Marcia and Calpurnia craters (Fig. 17).

However, there are many other groupings of grooves and crater chains that are not clearly radial to an impact crater. For example at $30^{\circ} \mathrm{N}, 160^{\circ} \mathrm{E}$, a set of wider, more prominent grooves cross-cut a set of more muted grooves and neither is clearly associated with an impact crater (Fig. 18). 


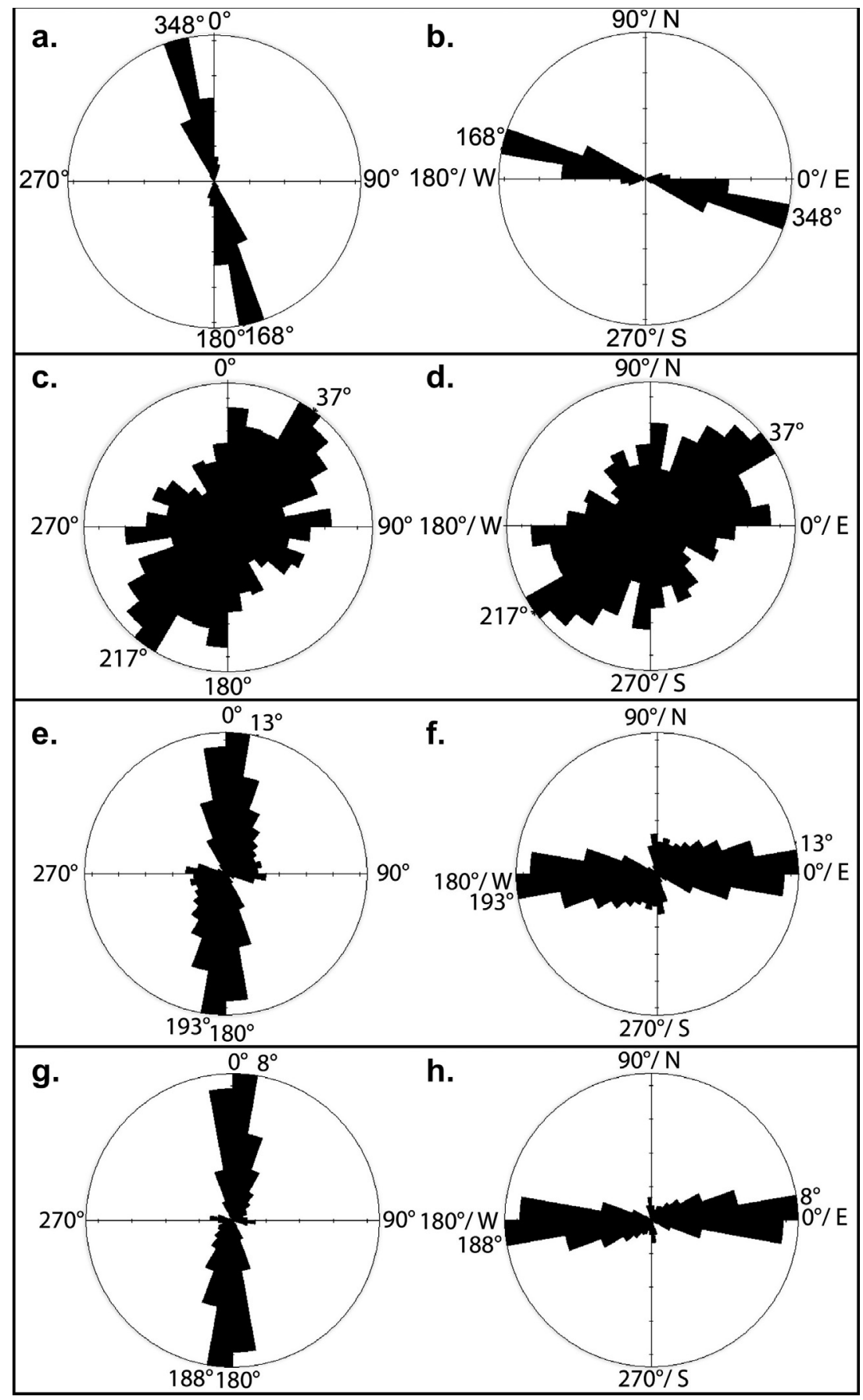

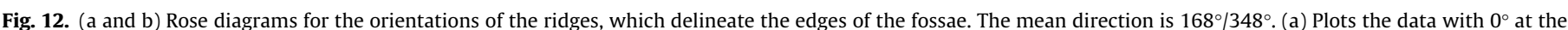

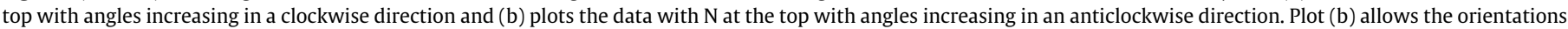

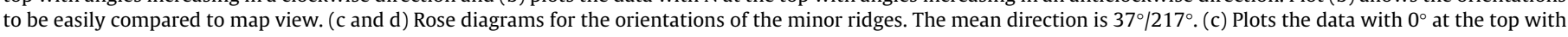

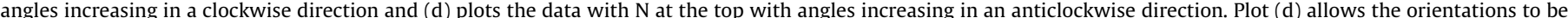

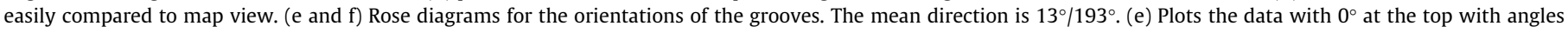

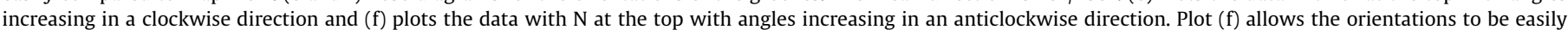

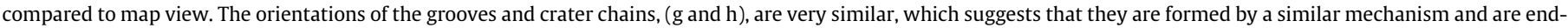

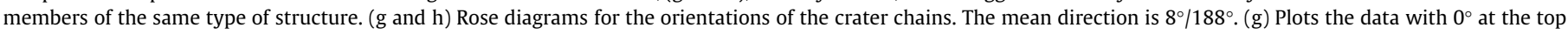

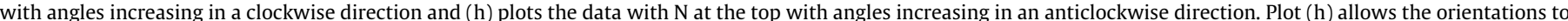

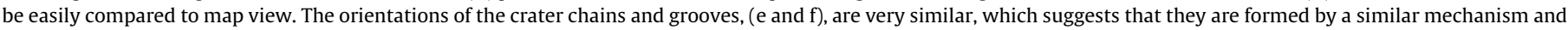
are end-members of the same type of structure.

4.3.3.2. Interpretation. The very similar orientations of the grooves and of the crater chains suggest that they were formed by a similar mechanism and are end-members of the same type of feature. Grooves and crater chains are commonly formed by secondary crater material from an impact scouring and bouncing across the surface, in which case the crater chains are secondary crater chains (e.g. Melosh, 2011). Along with the grooves, the secondary crater chains form ejecta ray systems. Some of the grooves and crater chains on Vesta are interpreted to form in this way. For example, the grooves and secondary crater chains (Fig. 16) radial to 


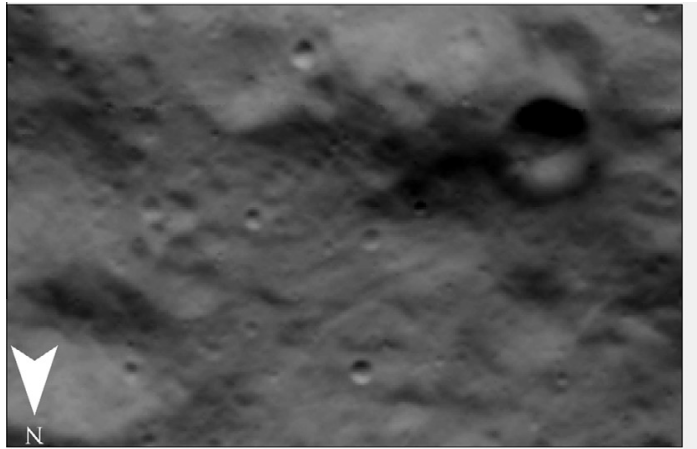

Legend

- $<6 \mathrm{~km}$ fresh rim crater

IIIIIIIIIII $>/=6 \mathrm{~km}$ heavily degraded subdued rim crater $\diamond \smile$ minor ridge

"m."m!n" $<6 \mathrm{~km}$ heavily degraded subdued rim crater
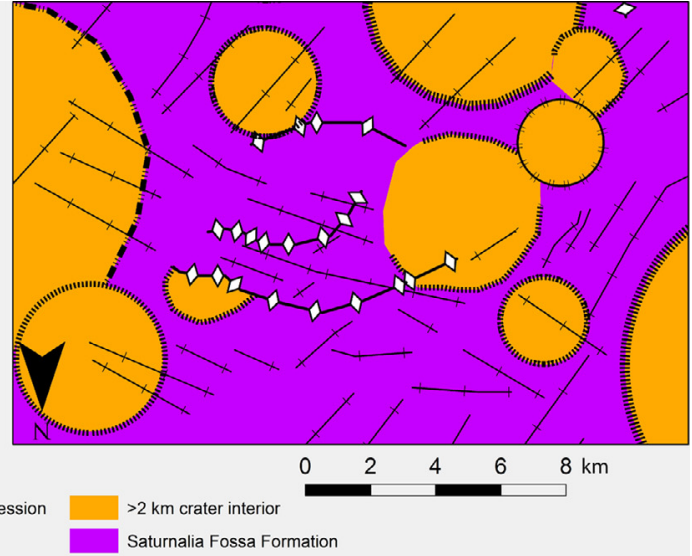

Saturnalia Fossa Formation

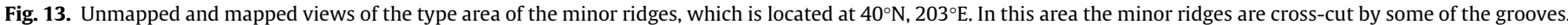
Also, one of the minor ridges in this area has been thrust over an older crater, which obscures a part of the crater.

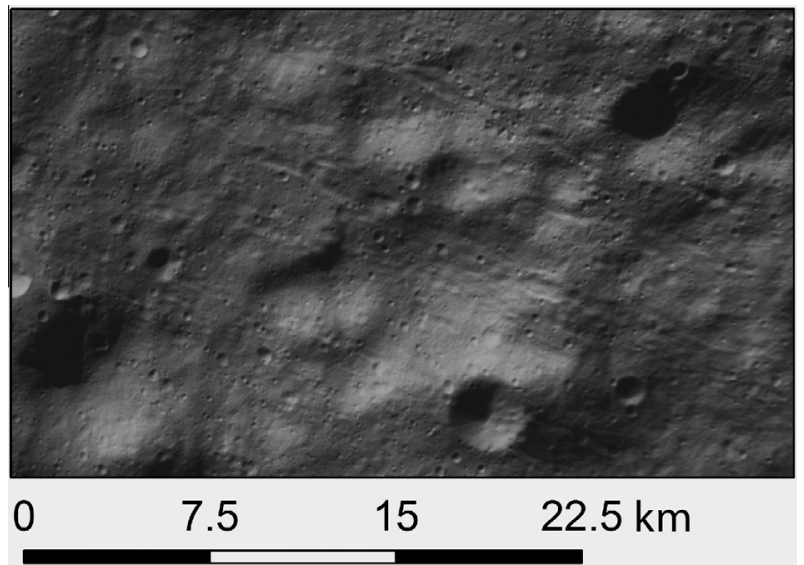

Fig. 14. Type area of the grooves, which is located at $23^{\circ} \mathrm{N}, 117^{\circ} \mathrm{E}$. There are many closely spaced grooves in this area.

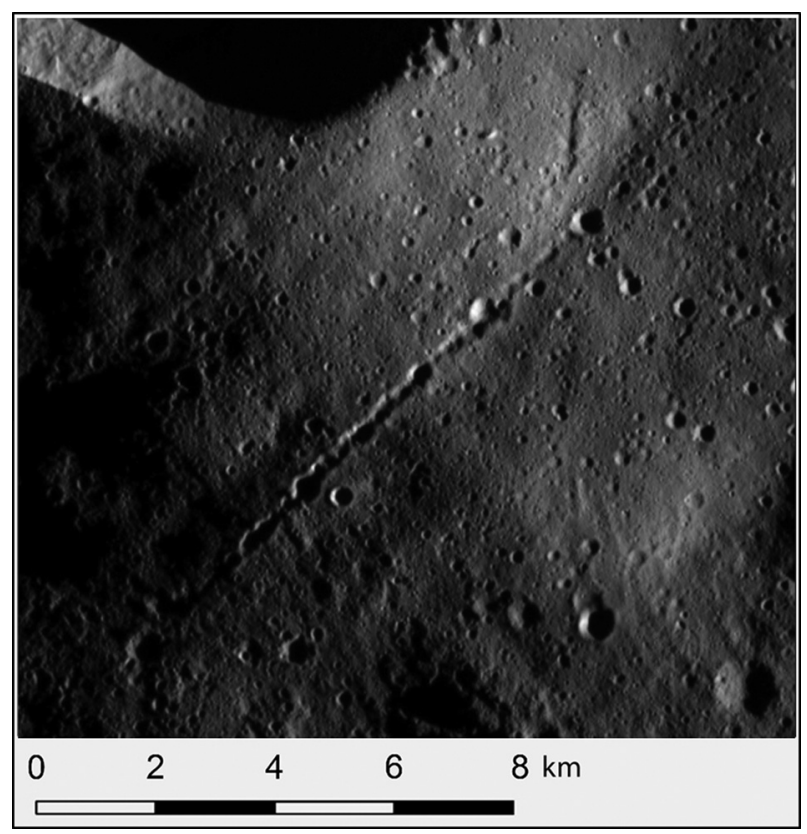

Fig. 15. Type area of the crater chains, which is located at $30^{\circ} \mathrm{N}, 173^{\circ} \mathrm{E}$. This chain is about $10 \mathrm{~km}$ long.
Calpurnia crater are likely a ray system formed by the ejection of secondary material from Calpurnia crater. Similarly, radial grooves located from $\sim 21^{\circ} \mathrm{N}$ to $\sim 43^{\circ} \mathrm{N}$ and $\sim 180^{\circ} \mathrm{E}$ to $\sim 220^{\circ} \mathrm{E}$ are likely part of the Marcia-Calpurnia ray system (Fig. 17).

Alternatively, many of the E-W trending grooves and crater chains and not oriented radially to an impact crater and may have a tectonic origin, which is supported by their very similar orientations (Fig. 12f and h). Pit crater chains on Earth and Mars are proposed to form by unconsolidated material draining down into extension fractures and/or dilational normal faults in a more consolidated material at depth (Ferrill et al., 2011; Wyrick et al., 2004). In this scenario the crater chains are pit crater chains and are the surface expression of funnels of down-draining material. The grooves represent a more even distribution of down-drained regolith. Hence, grooves and pit crater chains formed in this manner are the surface expression of extension fractures and/or dilational normal faults at depth.

The tectonic origin is supported by the similarity of the vestan grooves and pit crater chains to smaller-scale, more closely spaced linear structures of grooves and pit crater chains formed by normal faulting on the Moon (Fig. 19) (Watters et al., 2012). However, the grooves and pit crater chains on the Moon are more closely spaced than those on Vesta. This may be due to faulting occurring in a less dense material on Vesta; spacing is inversely controlled by the density of the crust, so that as the density decreases the spacing increases (e.g. Yin, 2000). Alternatively, since the thickness of the mechanical layer being faulted directly controls the fault spacing (e.g. Soliva et al., 2006; Montési and Zuber, 2003), faulting may be occurring in a thicker mechanical layer on Vesta.

Most of the grooves and crater chains likely have a tectonic origin but further work is necessary to identify if there are more groove and secondary crater chain ray systems.

\section{Discussion}

Our study, based mainly on photogeologic structural mapping, leads to the following main findings:

1. Eight geomorphic units are classified in Caparronia and Domitia quadrangles, based on morphology, cross-cutting relationships, spectral properties and topographic properties. Each geomorphic unit is heavily influenced by impact cratering and/or impact-related processes.

2. The Saturnalia Fossae are the first-order dominant structure in Vesta's northern hemisphere, and are mainly located in Domitia quadrangle. The fossae have a mean direction of ESE-WNW. 


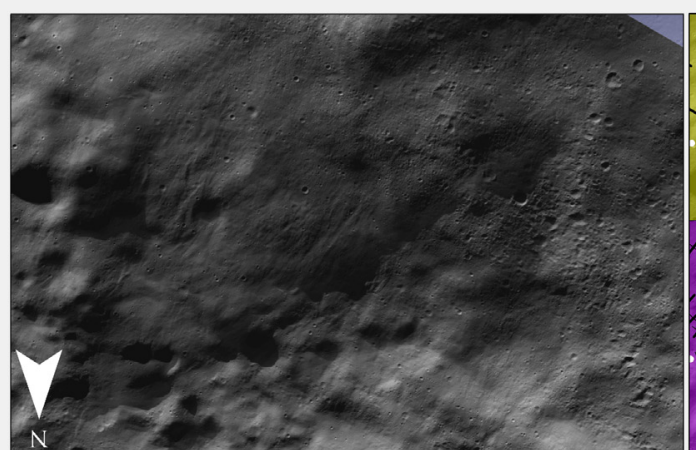

Legend

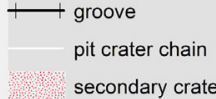

secondary craters

dark lobate unit
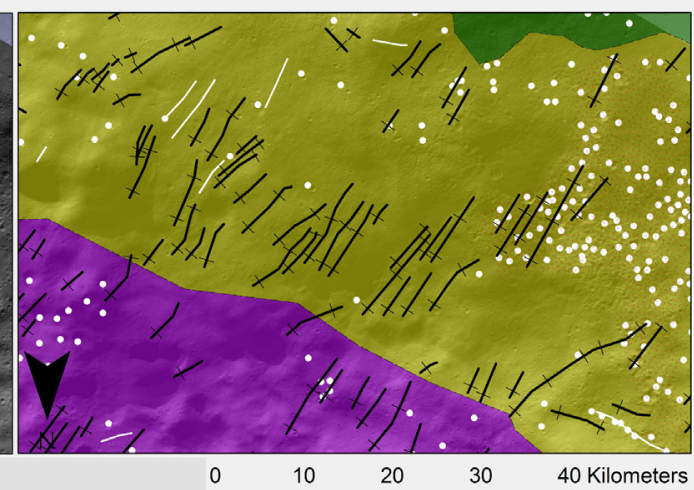

$20 \quad 30$

40 Kilometers

undifferentiated ejecta unit

approximate contact Saturnalia Fossa Formation

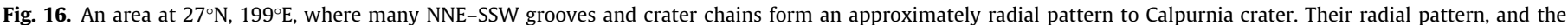

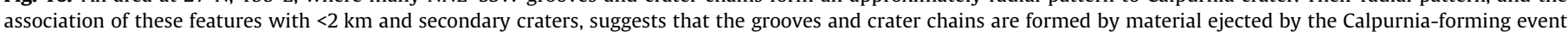
scouring and bouncing across the surface.
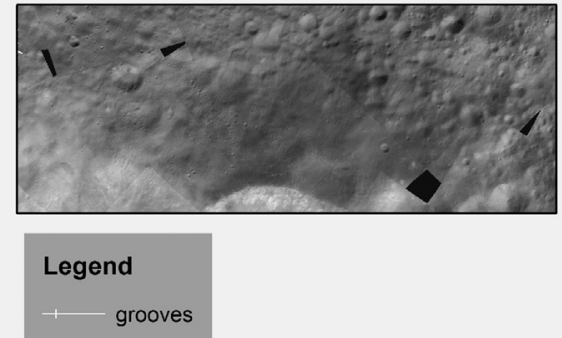
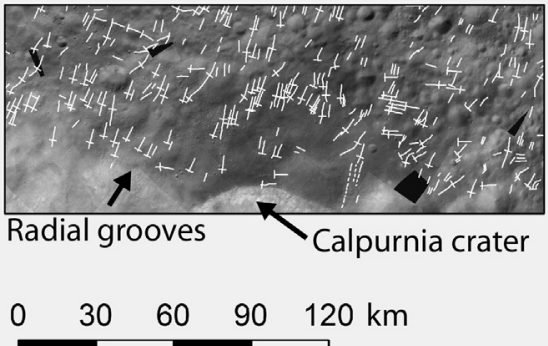

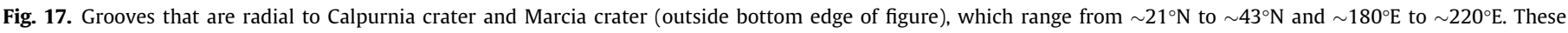
grooves are likely part of the Marcia-Calpurnia ray system, formed by secondary material ejected from the crater(s) scouring the surface.

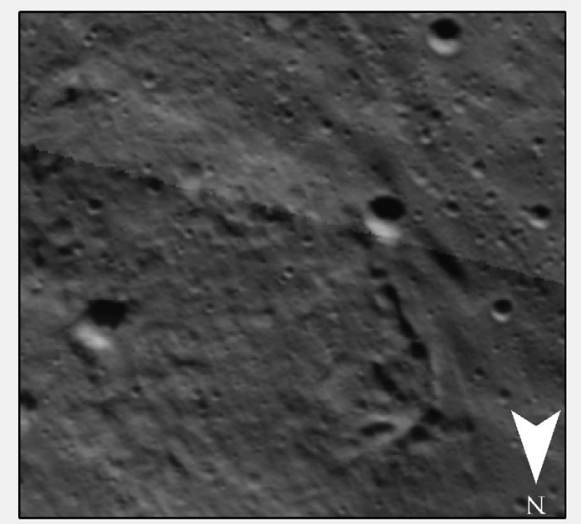

Legend

grooves muted grooves

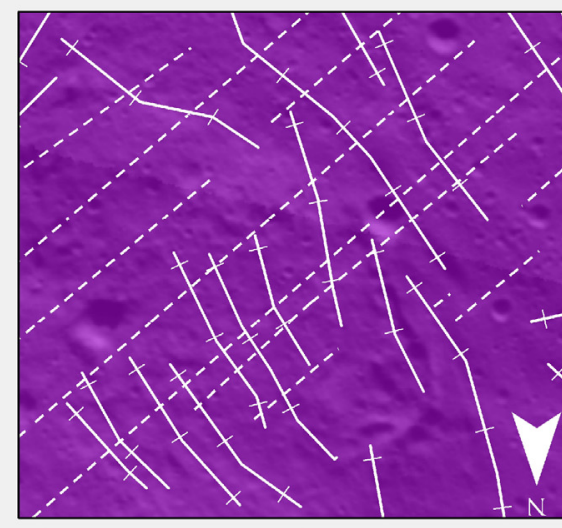

$8 \mathrm{~km}$

Saturnalia Fossa Formation

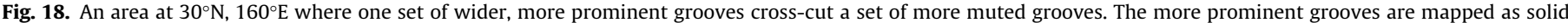

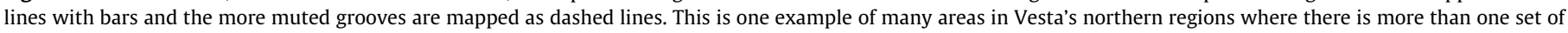
grooves with different orientations and different ages. Neither is clearly associated with an impact crater.

Saturnalia Fossa A is the largest, with a maximum width of $\sim 43 \mathrm{~km}$, and is interpreted to be a graben. Fossa B-E are smaller, with a maximum width of $\sim 15 \mathrm{~km}$, and are interpreted to be half-grabens formed by synthetic faults.
3. Second-order, adjacent structures also occur in the northern hemisphere and comprise of minor ridges ( $\sim 2 \mathrm{~km}$ to $\sim 25 \mathrm{~km}$ in length), grooves ( $\sim 3 \mathrm{~km}$ to $\sim 25 \mathrm{~km}$ in length) and crater chains ( $\sim 1 \mathrm{~km}$ to $\sim 25 \mathrm{~km}$ in length). 

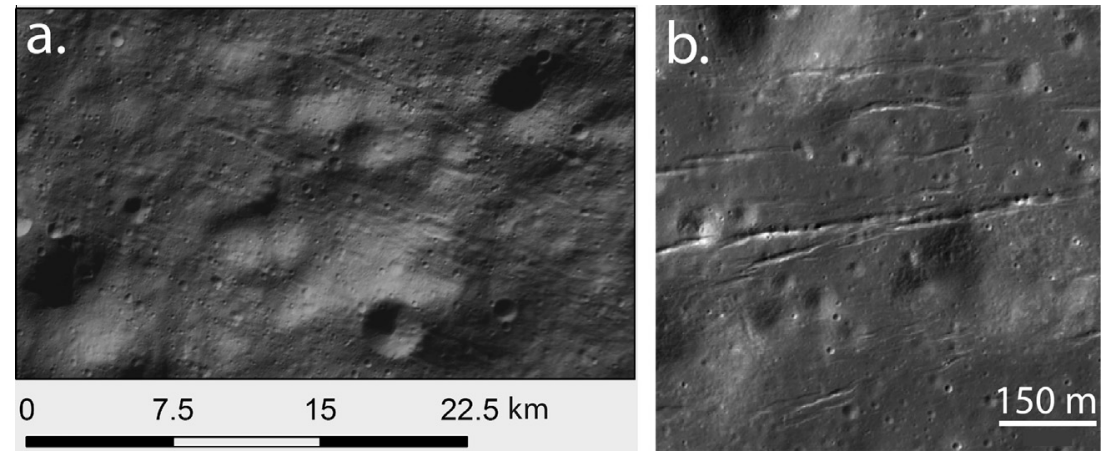

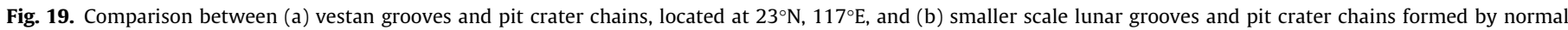

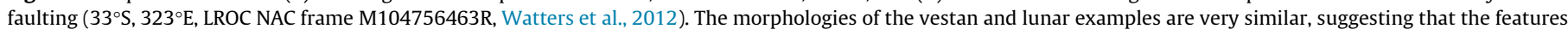
may have a similar origin and that many of the vestan grooves and crater chains may have a tectonic origin.
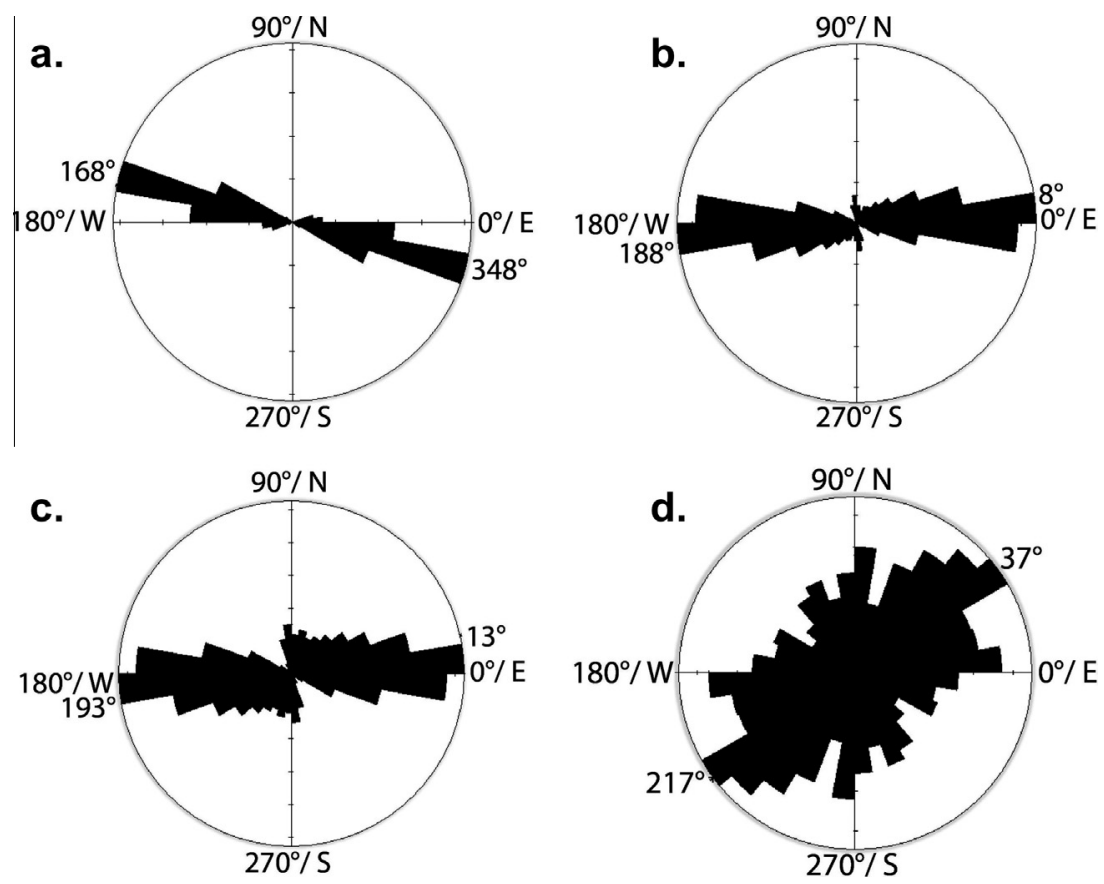

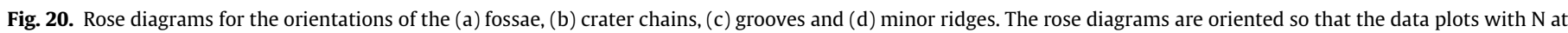
the top and angles increasing in an anticlockwise direction.

4. Minor ridges are divided into two groups, based on orientation: one group is approximately aligned $\mathrm{E}-\mathrm{W}$, while another group is approximately aligned NE-SW and N-S. The E-W group are interpreted as accumulations of regolith, formed by material flowing and then piling up under the control of the regional slope. The NE-SW and N-S group are interpreted as wrinkle ridges, which form under the control of sub-surface thrust faults.

5. Grooves and crater chains have very similar dominant orientations, both E-W, which suggests that they are end-members of the same type of feature. Many E-W trending grooves and crater chains are interpreted to have a tectonic origin, in which case the crater chains are pit crater chains that form by regolith draining down in a funnel shape into extension fractures and/or dilational normal faults at depth, while the grooves represent a more even down-draining. However, some grooves and crater chains, which are oriented radially around an impact crater, are interpreted to form by secondary crater material ejected from the primary impact crater bouncing and scouring across the surface.

Based on the above observations and interpretations, we propose the following history for the geologic and geomorphological evolution of the study area: the structures identified here can be classified into two stages of formation, by the scale of impact that is interpreted to have formed them and by their relative temporal relationships. In this section large-scale impacts are defined as impact craters with diameters of $>100 \mathrm{~km}$ and small-scale and medium-scale impacts are defined as impact craters with diameters of $<100 \mathrm{~km}$.

\subsection{Stage 1: formation of Saturnalia Fossae by the large-scale Veneneia impact}

The fossae are interpreted to be older than the adjacent structures because of cross-cutting relationships and morphology. As can be seen in the geologic maps (Figs. 5 and 6) the adjacent structures are well distributed both inside and outside of the fossae. If the adjacent structures formed prior to or synchronously with the fossae the large offsets, of at least $\sim 2 \mathrm{~km}$, necessary for the formation of the fossae would have deformed or erased the adjacent structures in a way that is not observed. Also, since the adjacent structures are significantly shallower and smaller than the fossae (discussed in Section 4, Results), they would have been modified or erased at a much greater rate than is observed if they 


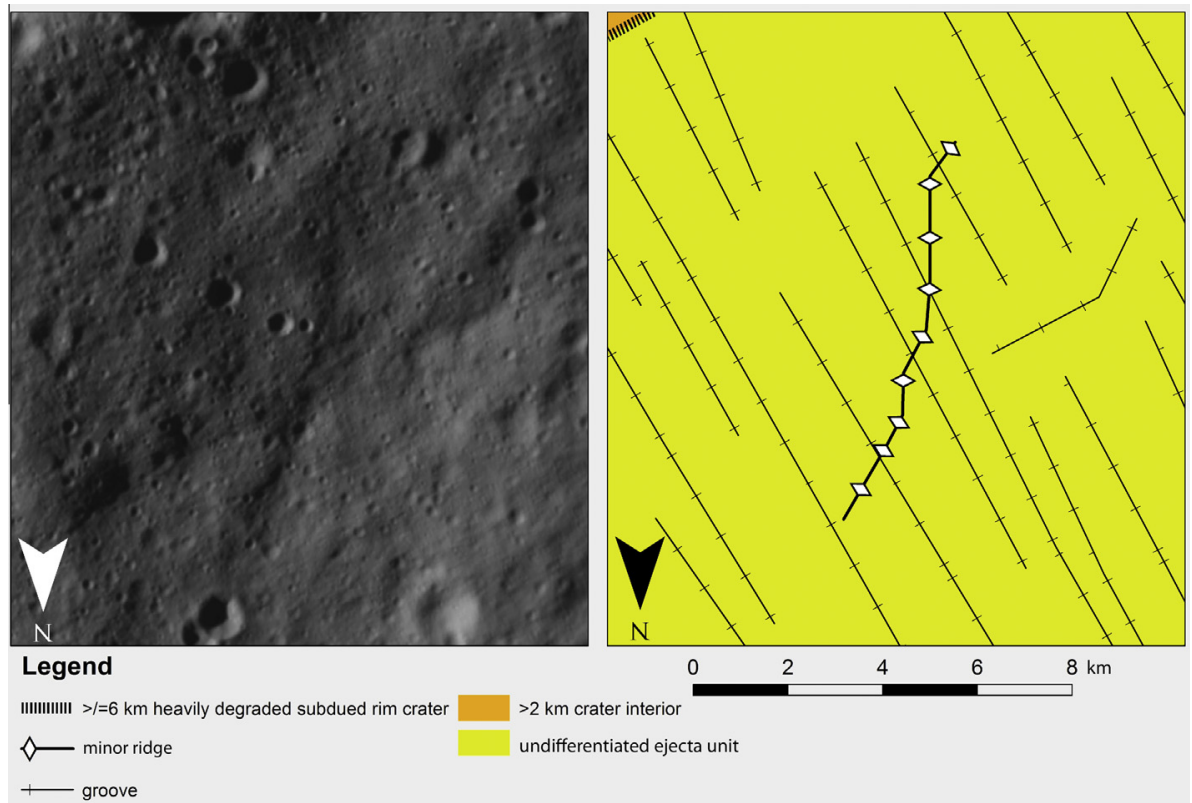

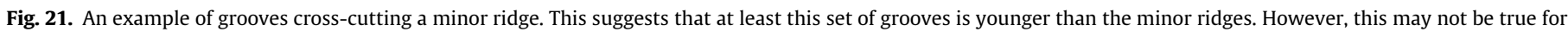
all of the sets of grooves that have been mapped on Vesta.

formed synchronously with the fossae. As discussed in Section 2, Background, the Saturnalia Fossae were induced by the Veneneia-forming impact (Jaumann et al., 2012; Buczkowski et al., 2012; Bowling et al., 2013). Thus, since the Veneneia impact basin is the second largest impact basin/crater on Vesta's surface, with a diameter of $450 \mathrm{~km}$ (Schenk et al., 2012), the formation of the Saturnalia Fossae was induced by a largescale impact into Vesta's surface.c

\subsection{Stage 2a: formation of a sub-set of adjacent structures by the large-scale Rheasilvia impact}

Formation of a sub-set of the adjacent structures is interpreted to have been induced by the Rheasilvia impact. This sub-set of adjacent structures are the minor ridges that are oriented NE-SW and N-S, which is approximately orthogonal to most of the grooves and crater chains, which are oriented E-W (Fig. 20). Many of the E$\mathrm{W}$ grooves and crater chains are interpreted as the surface expression of extension fractures and/or dilational normal faults at depth and thus have a tectonic origin. The NE-SW and $\mathrm{N}-\mathrm{S}$ minor ridges are interpreted to be thrust faults and consequently are also interpreted to have a tectonic origin. Thus, since extension fractures form approximately orthogonal to thrust faults in a shear zone (e.g., Sylvester, 1988), these structures are oriented as if they formed due to simple shear. Consequently, the shear over most of the surface of Vesta, which was a result of the Rheasilvia-forming impact (Bowling et al., 2013), may have formed the orthogonally oriented sub-set of the minor ridges, grooves and pit crater chains in Vesta's northern hemisphere. Therefore, since the Rheasilvia impact basin is the largest impact basin/crater on Vesta's surface, with a diameter of $500 \mathrm{~km}$ (Schenk et al., 2012), the formation of this sub-set of adjacent structures was also induced by a largescale impact into Vesta's surface.

5.3. Stage $2 b$ : formation of another sub-set of adjacent structures by small-scale and medium-scale impacts

The formation of the remaining adjacent structures is interpreted to be induced by small-scale and medium-scale impacts. As discussed in Section 4, some of the grooves and crater chains are oriented radially around impact craters and the ejection of secondary material from these small-scale and medium-scale craters is interpreted to have formed these grooves and crater chains. Furthermore, the E-W aligned minor ridges are interpreted to form by regolith accumulations under the control of regional slope. A likely mechanism for the initiation of movement of regolith on Vesta is seismic shaking from nearby impacts (e.g. Jaumann et al., 2012). For the minor ridges in this study, near-by impact craters are located in the northern hemisphere. All of these craters are $<100 \mathrm{~km}$ in diameter and are therefore classified as small-scale and medium-scale.

A principal temporal relationship between the two sub-sets of adjacent structures is not apparent from cross-cutting relationships. Thus, they are defined as stage $2 \mathrm{a}$ and $2 \mathrm{~b}$. In a certain area a set of grooves cross-cut the minor ridges (Fig. 21), which implies that in this area the minor ridges are older than the grooves and crater chains, since the end-member relationship of the grooves and crater chains suggests that they formed synchronously. However, this relationship may not be consistent for all of the minor ridges, grooves and crater chains since not all of the groupings of adjacent structures and cross-cutting relationships between them have been identified.

\section{Conclusions}

Vesta's low gravity and internal differentiation have resulted in the surface being dominated by impact-cratering and impact-related processes. Each of the eight geomorphic units identified in Caparronia and Domitia quadrangles, (1) Vestalia Terra unit, (2) cratered highlands unit, (3) Saturnalia Fossae trough unit, (4) Saturnalia Fossae cratered unit, (5) undifferentiated ejecta unit, (6) dark lobate unit, (7) dark crater ray unit and (8) lobate crater unit, are either modified by impact cratering processes, directly formed by impact cratering processes or produced by impact-induced processes.

Furthermore, impact-induced processes of a variety of scales form the structural features mapped in Vesta's northern hemisphere. Vesta's unique combination of low gravity and internal differentiation facilitated the formation of the Saturnalia Fossae, which are interpreted to be induced by the formation of the large-scale Veneneia impact basin. In contrast, a sub-set of the adjacent structures, which can be divided into minor ridges, 
grooves and pit crater chains, is interpreted to be induced by the formation of the large-scale Rheasilvia impact basin. This demonstrates that large-scale impacts can induce the formation of smaller scale structural features on Vesta as well as large-scale fossae. Finally, small-scale and medium-scale impacts also form another sub-set of adjacent structures, which are divided into minor ridges, grooves and crater chains, through the scouring of secondary material and accumulation of regolith due to seismic shaking.

By examining the nature of large and small structures in Vesta's northern hemisphere, and their connections to impacts of a variety of scales throughout Vesta's surface, we have explored the link between impact cratering and structural processes. This link is expressed in a unique way on Vesta due to its intermediate status in the Solar System as a differentiated asteroid with lower gravity than other, larger, differentiated bodies.

\section{Acknowledgments}

We thank NASA and the Dawn Flight Teams at JPL for the development, cruise, orbital insertion and operations of the Dawn spacecraft at Vesta. We also thank the instrument teams at the Max Planck Institute, German Aerospace Center (DLR), Italian National Institute for Astrophysics (INAF) and Planetary Science Institute for the acquisition and processing of Dawn data used in this work. The data used in this paper are available from the website http:// dawndata.igpp.ucla.edu.

\section{Appendix A. Supplementary material}

Supplementary data associated with this article can be found, in the online version, at http://dx.doi.org/10.1016/j.icarus.201 4.01.013.

\section{References}

Asphaug, E., Moore, J.M., Morrison, D., Benz, W., Nolan, M.C., Sullivan, R.J., 1996. Mechanical and geological effects of impact cratering on Ida. Icarus 120, 158184.

Binzel, R.P. et al., 1997. Geologic mapping of Vesta from 1994 Hubble Space Telescope images. Icarus 128, 95-103.

Bowling, T., Johnson, B.C., Melosh, H.J., 2013. Formation of the equatorial graben following the Rheasilvia impact on Asteroid 4 Vesta. Lunar Planet. Sci. XXXXIV. Abstract 1673

Buczkowski, D.L., Barnouin, O.S., Prockter, L.M., 2008. 433 Eros lineaments: Global mapping and analysis. Icarus 193, 39-52.

Buczkowski, D.L. et al., 2012. Large-scale troughs on Vesta: A signature of planetary tectonics. Geophys. Res. Lett. 39, L18205.

Buczkowski, D.L. et al., 2013. The geology of Vesta quadrangle Av-9 Numisia: Evaluating the unique geomorphology and physical properties of the Vestalia Terra plateau. Icarus, this issue.

De Sanctis, M.C. et al., 2011. The VIR spectrometer. Space Sci. Rev. 163, 329-369.

De Sanctis, M.C. et al., 2012. Spectroscopic characterization of mineralogy and its diversity across Vesta. Science 336, 697-700.

Federal Geographic Data Committee [prepared for the Federal Geographic Data Committee by the U.S. geological Survey], 2006. FGDC Digital Cartographic Standard for Geologic Map Symbolization. Federal Geographic Data Committee. p. 290.

Ferrill, D.A., Wyrick, D.Y., Smart, K.J., 2011. Coseismic, dilational-fault and extension-fracture related pit chain formation in Iceland: Analog for pit chains on Mars. Lithosphere 3, 133-142.

Gaffey, M.J., 1997. Surface lithologic heterogeneity of Asteroid 4 Vesta. Icarus 127, $130-157$.

Gaskell, R.W., 2012. SPC shape and topography of Vesta from DAWN imaging data. Div. Planet. Sci. XXXXIV. Abstract 209.03.

Golombek, M.P., Anderson, F.S., Zuber, M.T., 2001. Martian wrinkle ridge topography: Evidence for subsurface faults from MOLA. J. Geophys. Res. 106 (E10), 23811-23821.

Jaumann, R, et al., 2012. Vesta's shape and morphology. Science 336, 687-690.

Kahn, E.G. et al., 2011. A tool for the visualization of small body data. Lunar Planet. Sci. XXXXII. Abstract 1618
Li, J.-Y. et al., 2010. Photometric mapping of Asteroid (4) Vesta's southern hemisphere with Hubble Space Telescope. Icarus 208, 238-251.

Marchi, S. et al., 2012. The violent collisional history of Asteroid 4 Vesta. Science 336, 690-694.

McCord, T.B., Adams, J.B., Johnson, T.V. 1970. Asteroid Vesta: Spectral reflectivity and compositional implications. Science 168, 1445-1447.

McCord, T.B. et al., 2012. Dark material on Vesta from the infall of carbonaceous volatile-rich material. Nature 491, 83-86.

McSween, H.Y., Mittlefehldt, D.W., Beck, A.W., Mayne, R.G., McCoy, T.J., 2011. HED meteorites and their relationship to the geology of Vesta and the Dawn mission. Space Sci. Rev. 163, 141-174.

Melosh, H.J., 2011. Planetary Surface Processes. Cambridge University Press, p. 245

Montési, L.G.J., Zuber, M.T., 2003. Spacing of faults at the scale of the lithosphere and localization instability: 1. Theory. J. Geophys. Res. 108, B22110.

Pieters, C.M. et al., 2012. The distinctive space weathering on Vesta. Nature 491, 79_ 82.

Plescia, J.B., Golombek, M.P., 1986. Origin of planetary wrinkle ridges based on the study of terrestrial analogs. Geol. Soc. Am. Bull. 11, 1289-1299.

Prettyman, T.H. et al., 2011. Dawn's gamma ray and neutron detector. Space Sci. Rev. 163, 371-459.

Prettyman, T.H. et al., 2012. Elemental mapping by Dawn reveals exogenic $\mathrm{H}$ in Vesta's regolith. Science 338, 242-246.

Preusker, F. et al., 2012a. The northern hemisphere of Asteroid (21) Lutetia Topography and orthoimages from Rosetta OSIRISNAC image data. Planet. Space Sci. 66, 54-63.

Preusker, F. et al., 2012b. Stereo-photogrammetrically derived topography of Asteroid (4) Vesta. Am. Geophys. Union. XXXXV. Abstract P43E-05.

Prockter, L.P. et al., 2002. Surface expressions of structural features on Eros. Icarus 155, 75-93.

Reddy, V. et al., 2012a. Albedo and color heterogeneity of Vesta from Dawn. Science 336, 700-704.

Reddy, V. et al., 2012b. Delivery of dark material to Vesta via carbonaceous chondritic impacts. Icarus 221, 544-559.

Reddy, V. et al., 2013. Comparing Dawn, Hubble Space Telescope, and ground-based interpretations of (4) Vesta. Icarus 226, 1103-1114.

Roatsch, T.H. et al., 2012. High resolution Vesta High Altitude Mapping Orbit (HAMO) Atlas derived from Dawn framing camera images. Planet. Space Sci. 73, 283-286.

Ruesch, O. et al., 2013. Geologic map of the northern hemisphere of Vesta based on Dawn FC images. Icarus, this issue.

Russell, C.T. et al., 2012. Dawn at Vesta: Testing the protoplanetary paradigm. Science 336, 684-686.

Schenk, P. et al., 2012. The geologically recent giant impact basins at Vesta's South Pole. Science 336, 694-697.

Schröder, S.E. et al., 2013. In-flight calibration of the Dawn framing camera. Icarus 226, 1304-1317.

Schröder, S.E. et al., 2014. In-flight calibration of the Dawn framing camera II: Flat fields and stray light correction. Icarus, submitted for publication.

Sierks, H. et al., 2011. The Dawn framing camera. Space Sci. Rev. 163, 263-327.

Soliva, R., Benedicto, A., Maerten, L., 2006. Spacing and linkage of confined normal faults: Importance of mechanical thickness. J. Geophys. Res. 111, B01402.

Sylvester, A.G., 1988. Strike-slip faults. Geol. Soc. Am. Bull. 100, 1666-1703.

Thomas, P.C., Binzel, R.P., Gaffey, M.J., Storrs, A.D., Wells, E.N., Zellner, B.H., 1997. Impact excavation on Asteroid 4 Vesta: Hubble Space Telescope results. Science 277, 1492-1495.

Thomas, N. et al., 2012. The geomorphology of (21) Lutetia: Results from the OSIRIS imaging system onboard ESA's Rosetta spacecraft. Planet. Space Sci. 66, 96-124.

Twiss, R.J., Moores, E.M., 2007. Structural Geology, second ed. W.H. Freeman and Company, p. 736.

Varnes, D.J., 1978. Slope movement types and processes. In: Schuster, R.L., Krizek, R.J. (Eds.), Landslides-Analysis and Control. Transportation Research Board, Special Report, 176. National Research Council, Washington, DC, pp. 11-33.

Vincent, J.-B. et al., 2012. Crater depth-to-diameter ration and surface properties of (4) Vesta. Lunar Planet. Sci. XXXXIII. Abstract 1415

Watters, T.R. et al., 2009. The tectonics of Mercury: The view after MESSENGER's first flyby. Earth Planet. Sci. Lett. 285, 283-296.

Watters, T.R. et al., 2010. Evidence of recent thrust faulting on the Moon revealed by the Lunar Reconnaissance Orbiter Camera. Science 329, 936-940.

Watters, T.B., Robinson, M.S., Banks, M.E., Tran, T., Denevi, B.W., 2012. Recent extensional tectonics on the Moon revealed by the Lunar Reconnaissance Orbiter Camera. Nat. Geosci., http://dx.doi.org/10.1038.

Williams, D.A., Yingst, R.A., Garry, W.B., 2013. Introduction: The geologic mapping of Vesta. Icarus, this issue.

Wyrick, D., Ferrill, D.A., Morris, A.P., Colton, S.L., Sims, D.W., 2004. Distribution, morphology and origins of martian pit crater chains. J. Geophys. Res. 109, E06005.

Yin, A., 2000. Mode of Cenozoic east-west extension in Tibet suggesting a common origin of rifts in Asia during the Indo-Asian collision. J. Geophys. Res. 105, 21475-21759.

Yingst, R.A. et al., 2014. Geologic mapping of Vesta. Planet. Space Sci., in press. 